\title{
A Cryogenic Milling Method to Fabricate Nanostructured
}

\author{
Anodes \\ Qizhang Yan', Shu-Ting Ko², Yumin Zhao', Grace Whang³, Andrew \\ Dawson ${ }^{4}$, Sarah H. Tolbert ${ }^{3,4}$, Bruce S. Dunn³, and Jian Luo ${ }^{1,2, *}$ \\ 'Department of Nanoengineering; ${ }^{2}$ Program of Materials Science and \\ Engineering, University of California San Diego, La Jolla, California 92093, \\ U.S.A. \\ ${ }^{3}$ Department of Materials Science and Engineering; ${ }^{4}$ Department of Chemistry \\ and Biochemistry, University of California, Los Angeles, California 90095,
}

U.S.A.

\begin{abstract}
Cryogenic milling was demonstrated as a new and facile method to fabricate nanostructured battery electrode materials. SnSb anode material with $1.2 \mathrm{wt} \%$ graphite was selected as a model system to demonstrate the feasibility and benefits of this method. Ball milling at a cryogenic temperature can suppress cold welding, exfoliate bulk graphite powder into nanoplatelets, and evenly disperse them between the grains. Aberrationcorrected scanning transmission electron microscopy and post-cycling scanning electron microscopy showed refined grain sizes and well-dispersed carbon nanoplatelets, which can stabilize the nanostructure and alleviate volume expansion and cracking upon cycling. The cryomilled $\mathrm{SnSb}-\mathrm{C}$ composite anode showed a reversible volumetric capacity of 1842 $\mathrm{Ah} / \mathrm{L}$, average coulombic efficiency of $99.6 \pm 0.3 \%$, and capacity retention of $90 \%$ over 100 cycles. The cryomilled sample showed improved electrochemical performance compared to the conventional ball milled specimen. This new method of cryogenic milling can produce various other high-performance nanostructured electrode materials.
\end{abstract}

Keywords: lithium-ion batteries, anode material, alloy anode, cryomilling, ball milling

\footnotetext{
* Corresponding author. E-mail address: jluo@alum.mit.edu (J. Luo).
} 


\section{Introduction}

The development of rechargeable energy storage systems has played a crucial role in advancing portable electronic devices and electric vehicles. For the past three decades, carbon-based anodes were mainly used due to their good electronic conductivity and

cycling stability. ${ }^{1}$ However, the theoretical gravimetric and volumetric capacities of graphite, $372 \mathrm{~m} \mathrm{Ah} / \mathrm{g}$ and $756 \mathrm{Ah} / \mathrm{L}$, are major limitations to attain higher energy density batteries. To further increase the cell energy density, researchers have studied Li-alloying reactions with metal or semi-metal elements and various intermetallic compounds. Various strategies, such as nanoporous structures, ${ }^{2-4}$ inactive matrix composites,,${ }^{5,6}$ and carbon composites, ${ }^{7-9}$ have been proposed to alleviate the extreme volume change $(>200 \%)$ during cycling.

To fabricate carbon composite structures, mechanical alloying via ball milling is widely used due to its simplicity. Several groups have demonstrated the successful synthesis of Sn-M-C composites $\left(\mathrm{M}=\right.$ metal $^{7-9}$ and $\mathrm{Si}-\mathrm{C}$ composites $^{10-12}$ that showed higher specific capacity compared to the graphite anode. However, the volumetric capacities of these composites are often limited by the amount of carbon added. In 2005, Sony announced the "Nexelion" cell that utilized an amorphous Sn-Co carbon composite as the anode for a portable camcorder ${ }^{13}$. It improved the volumetric energy density by $10 \%$ compared to $\mathrm{LiCoO}_{2} /$ graphite cells $^{14}$. While the composition of the anode material was not disclosed, researchers suggested a composition of $\mathrm{Sn}: \mathrm{Co}: \mathrm{C}=3: 3: 4(\mathrm{~mol})$ fabricated through highenergy ball milling (HEBM $)^{6,15,16}$. This corresponds to $10 \mathrm{wt} \%$, or $27 \mathrm{vol} \%$, of graphite added during the ball milling process. While the added carbon can help to alleviate the volume expansion from the cycling process, it decreases the full cell volumetric energy density. Unfortunately, due to the heat generated from the ball milling process, decreasing the carbon content in traditional HEBM can increase cold-welding of the metal grains, especially for the low melting temperature metals such as Sn. This can increase both the grain size and the secondary particle $\operatorname{size}^{17}$, which are undesirable for battery applications ${ }^{14,18}$. Therefore, a new processing route is needed to fabricate anode particles with desired micro- and nano-nanostructures. 
In this study, we demonstrate a new route using cryogenic milling (cryomilling) to fabricate nanostructured alloy anodes. Cryomilling is a cost-effective manufacturing method that is already widely used in the food industry, ${ }^{19,20}$ in polymer powder synthesis, ${ }^{21}$ and in the fabrication of nanostructured alloys. ${ }^{22}$ Due to the presence of a ductile-to-brittle transition for many materials at low temperatures, cryomilling can efficiently alleviate cold-welding and reduce the grain and particle size ${ }^{23}$. Previous studies have also suggested that cryomilling can promote the uniform distribution of various types of carbon between metal grains for mechanical properties enhancements ${ }^{24-26}$. To demonstrate the feasibility and the benefits of cryomilling on the fabrication of battery anode materials, the $\mathrm{SnSb}$ intermetallic was selected as a model system. SnSb has attracted considerable attention due to its high theoretical capacity of $825 \mathrm{mAh} / \mathrm{g}$. Additionally, researchers have found the two-step lithiation reaction of $\mathrm{SnSb}$ can create a $\mathrm{Li}_{3} \mathrm{Sb}$ matrix structure to buffer the volume expansion and improve the cycling stability ${ }^{27-29}$. However, cracks can often form in micrometer-size $\mathrm{SnSb}$ particles during cycling, resulting in capacity decay upon cycling ${ }^{28}$.

Here, we compare the synthesis of SnSb-C composite using three ball milling methods: high-energy ball milling or HEBM, (lower energy) planetary ball milling, and cryomilling. SnSb-C composite fabricated with HEBM showed severe cold-welding and an average particle size $>100 \mu \mathrm{m}$. The composite made with the planetary ball milling demonstrated poor cycling stability. In contrast, cryomilling led to the synthesis of high-energy density $\mathrm{SnSb}-\mathrm{C}$ anode in one step. Aberration-corrected scanning transmission electron microscopy (AC STEM) and post-cycling SEM revealed that the refined grain size and well-dispersed carbon nanoplatelets effectively alleviate the volume expansion and prevent particle cracking after cycling. This work thus demonstrates a new and potentially general method to fabricate practical nanostructured battery electrodes that can be applied to various materials.

\section{Experimental Section}

Material Synthesis. The SnSb-C composites were prepared by various ball milling routes. $48.78 \mathrm{wt} \% \mathrm{Sn}$ (Alfa Aesar, 99.80\%, 325 mesh), 50.02 wt.\% Sb (Alfa Aesar, 99.5\%, $200 \mathrm{mesh}$ ), and $1.2 \mathrm{wt} \%$ graphite (MTI) were used as starting materials. For cryomilling, $1.3 \mathrm{~g}$ starting material was placed in a stainless-steel jar $(50 \mathrm{ml})$ with 5 stainless-steel balls 
(5 mm diameter) inside an Ar-filled glovebox. After sample is pre-cooled for $15 \mathrm{~min}$, the milling process was performed for $4 \mathrm{~h} @ 25 \mathrm{~Hz}\left(1500 \mathrm{~min}^{-1}\right)(8$ cycles of 25 min each with an intermediate cooling of $5 \mathrm{~min}$ ) using a Retsch Cryomill. The jar is cooled with liquid nitrogen circulation during the pre-cooling and milling process. The milling temperature was constantly monitored with an "Autofill system" from the cryomill machine. For highenergy ball milling, $1.3 \mathrm{~g}$ starting material was placed in a stainless-steel jar $(65 \mathrm{ml})$ with 6 stainless-steel balls ( $5 \mathrm{~mm}$ diameter) inside an Ar-filled glovebox. The milling process was performed for $4 \mathrm{~h} @ 1200 \min ^{-1}$ ( 8 cycles of 25 min each with resting of 5 min) using a SPEX-8000D Mixer/Mill at room temperature. For planetary ball milling, $5 \mathrm{~g}$ starting material was placed in an yttrium stabilized zirconium oxide (YSZ) grinding jar (100 ml) with 12 YSZ grinding balls (10 mm diameter) inside an Ar-filled glovebox. The milling process was performed for $8 \mathrm{~h} @ 400 \mathrm{rpm}$ ( 16 cycles of $25 \mathrm{~min}$ each with resting of $5 \mathrm{~min}$ ) using a Across International PQ-N04 planetary ball mill at room temperature.

For sample comparison, the processing parameters (ball-to-powder ratio, jar volume/geometry, ball/jar material, milling time, and speed) of cryomilling and HEBM are similar. Therefore, the resulting powder comparison between HEBM and cryomill can demonstrate the benefits under cryogenic temperature.

Material Characterization. Scanning electron microscopy (SEM) images were taken with a FEI Apreo SEM operated at $5 \mathrm{kV}$. To characterize the crystal structure of the synthesized SnSb-C composite, X-ray powder diffraction (XRD) was conducted using a Bruker D2 Phaser $(\mathrm{Cu} \mathrm{K} \alpha$ radiation, $\lambda=1.5406 \AA$ ) with scanning rate of $0.5 \% \mathrm{~min}$. The grain size was calculated using the Scherrer Equation, and instrument peak broadening equals $0.1^{\circ}$. Single peak calculation at $29.1^{\circ}$ was performed. The pattern at $41.5^{\circ}$ and $51.4^{\circ}$ were combination of two diffraction peaks; therefore, a large estimated error was expected, and the calculation was not performed. $\mathrm{N}_{2}$ porosimetry was conducted with a Micrometritics TriStar II 3020. The sample pore volume was calculated from the adsorption branch of the isotherm using the Braet-Joyner-Halenda (BJH) model. Raman spectroscopy was taken using a Renishaw Raman with $633 \mathrm{~nm}$ laser. The transmission electron microscopy sample was fabricated with a dual-beam focused ion beam (FIB)/SEM system using a FEI Scios. The microstructures and elemental distribution of the cryomilled 
composite were further studied with aberration-corrected scanning transmission electron microscopy (AC-STEM) using a JEOL JEM-300CF STEM microscope operated at $300 \mathrm{kV}$ with double correctors and dual large angle energy dispersive X-ray spectroscopy (EDS) detector. The STEM and EDS data processing was performed with DigitalMicrograph (DM). For post-cycling particle morphology SEM characterization, the electrode after electrochemical cycling was disassembled using an MTI hydraulic crimper equipped with disassembling die inside an Ar-filled glovebox. The obtained electrode was rinsed with diethyl carbonate (DEC) solvent to remove residual electrolyte, and then dried inside glovebox antechamber under vacuum for $30 \mathrm{~min}$. To ensure air-free transfer into the SEM chamber, the sample is sealed inside a QuickLoader (FEI) in the glovebox and directly load into the SEM chamber.

Electrochemical Characterization. Each type of ball milled SnSb-C was mixed with carbon fiber (pyrolytically stripped, $>98 \%$ carbon basis, $D \times L=100 \mathrm{~nm} \times 20-200 \mu \mathrm{m}$ ) and carboxymethyl cellulose (CMC, MTI Corp) in water at a mass ratio of 8:1:1 using a Thinky mixer (ARE-310) for $2 \mathrm{~h}$ at $2000 \mathrm{rpm}$. The resulting homogeneous slurry was casted on a copper foil (9 $\mu \mathrm{m}$ thick, MTI Corp) using a doctor blade and an automatic tape casting coater at a constant traverse speed of $10 \mathrm{~mm} / \mathrm{s}$. The casted tape was first dried in air for 12 $\mathrm{h}$ then dried in a vacuum oven at $80{ }^{\circ} \mathrm{C}$ for $12 \mathrm{~h}$. After drying, the electrode was then punched into $11 \mathrm{~mm}$ discs and weighed individually. The average active material $(\mathrm{SnSb}-\mathrm{C}$ composite) loading was $1.50 \mathrm{mg} / \mathrm{cm}^{2}$. 2032-type coin cells were assembled with Li metal disc as counter/reference electrode and Celgard 2320 polypropylene membrane as separator. The electrolyte consists of $1 \mathrm{M}$ LiPF6 in a 1:1 ethylene carbonate/diethyl carbonate solvent (LP40, Sigma-Aldrich) with 5 vol\% fluorinated ethylene carbonate (FEC, Sigma-Aldrich). Galvanostatic cycling was conducted using a Lanhe battery cycler in the potential range of $0.05-1.5 \mathrm{~V}$ vs. $\mathrm{Li}^{+} / \mathrm{Li}$ at various current rates (listed in figures). The gravimetric capacity was calculated based on the loading of the active material ( $\mathrm{SnSb}-\mathrm{C}$ composite).

\section{Results and Discussion}

The cryomilling process used in this study based on having liquid nitrogen $\left(\mathrm{LN}_{2}\right)$ circulate outside the ball milling jar to continually cool the milling process (Figure 1b). 
This process can be viewed as a high-energy shaker mill with automatic $\mathrm{LN}_{2}$ cooling. The ball mill jar was cooled to $-196^{\circ} \mathrm{C}$ before the milling process. Additionally, 5 minutes of cooling was carried out after 25 minutes of ball milling to ensure the cryogenic processing temperature. The cryomilling process was first optimized with various milling times. $\mathrm{Sn}$ and $\mathrm{Sb}$ particles were added in 1:1 mol ratio with $1.2 \mathrm{wt} \%$ graphite. The starting composition was kept the same for all ball milling process. After $1 \mathrm{~h}$ of cryomilling $(2 \times 25$ min milling with 5 min intermediate cooling), unmixed graphite could still be observed in the SEM images, indicating insufficient mixing (Figure S1a). Sn (ICSD-106072) and Sb (ICSD-64695) phases were also seen in the product based on X-ray diffraction (XRD) (Figure S2a), further signifying that longer processing time was required. When the milling time increased to $4 \mathrm{~h}, \mathrm{SnSb}$ particles with maximum diameters of $7 \mu \mathrm{m}$ could be observed in the SEM image (Figure 2a, Figure S11a). The average particle size was estimated to be $1.84 \pm 1.29 \mu \mathrm{m}$ as shown in Figure S12a. In addition, no graphite flakes could be found, indicating most of the graphite was exfoliated and mixed between the grains. The diffraction patterns of the $4 \mathrm{~h}$ cryomilled sample could be indexed with SnSb (ICSD154085 ) in the $R \overline{3} \mathrm{~m}$ space group. The diffraction peaks corresponding to Sn and Sb mostly disappeared after $4 \mathrm{~h}$ of cryomilling, with only trace $\mathrm{Sb}$ diffraction remaining. The dominant $\mathrm{SnSb}$ diffraction peaks also became broader. This indicates cryomilling can be used to synthesize fine-grained $\mathrm{SnSb}$ particles.

(a) High-energy Ball Mill

(b) Cryogenic
Ball Mill

(c)

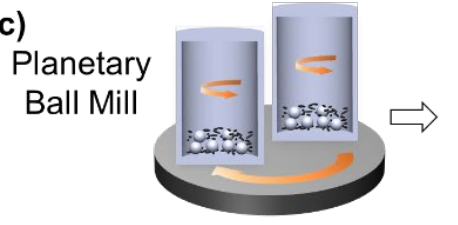

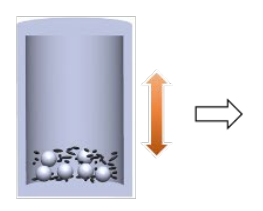
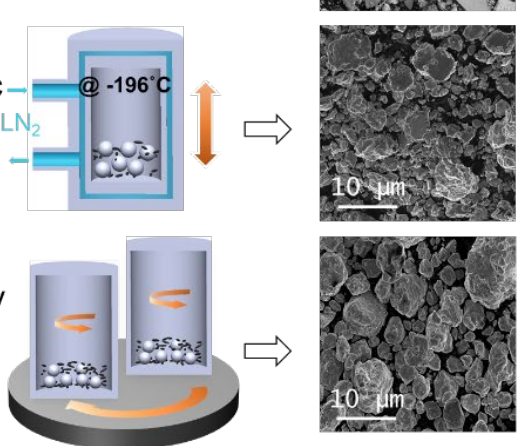

(d)

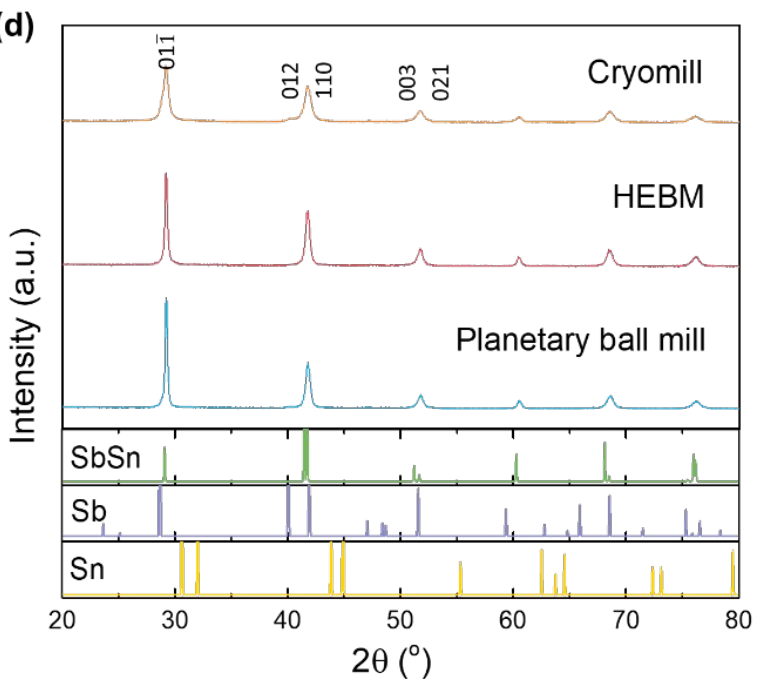

Figure 1. Synthesis method and SEM images of mechanical alloyed SnSb-C composite anodes fabricated through (a) high-energy ball mill, (b) cryogenic ball mill, and (c) 
planetary ball mill. (d) X-ray diffraction patterns comparing SnSb-C composite anodes synthesized through these three different mechanical methods. All methods produce SbSn, but the degree of crystallinity, as evidenced by the diffraction peak widths, varies dramatically between methods.

For comparison, HEBM and planetary ball milling were carried out with similar processing parameters (see Experimental Section). The resulting morphology and XRD comparison of SnSb-C composites are shown in Figure 1a, c, and d. All the ball milling process resulted in the formation of SnSb. After $4 \mathrm{~h}$ of $\operatorname{HEBM}(8 \times 25 \mathrm{~min}$ milling with 5 min intermediate rest), large particles of more than $100 \mu \mathrm{m}$ diameters could be commonly observed (Figure 1a, Figure S11e), indicating severe cold-welding during the milling process. The average particle size was estimated to be $22.12 \pm 28.91 \mu \mathrm{m}$ as shown in Figure S12c. Since planetary ball milling has lower energy, $8 \mathrm{~h}(16 \times 25$ min with $5 \mathrm{~min}$ intermediate rest) was required to mechanically alloy $\mathrm{SnSb}$ phase. The lower mixing energy also alleviated the cold-welding effect and resulted in smaller particle diameters (Figure 1c, Figure S11c). The average particle size was estimated to be $2.54 \pm 1.96 \mu \mathrm{m}$ as shown in Figure S12b. However, the lower milling energy also results in uneven mixing of graphite with the metal powder. In Figure S3, graphite flakes could still be observed after an $8 \mathrm{~h}$ planetary ball milling process. An additional benefit of the $\mathrm{LN}_{2}$ cooled shaker mill is that $4 \mathrm{~h}$ of cryomilling produced $<7 \mu$ m diameter particles with no obvious graphite observed. Moreover, the cryomilled powder showed broader diffraction peaks, which indicates a finer grain size (Table S1). Using the Williamson-Hall method, the averaged grain size of the cryomilled powder was estimated to be $23.5 \mathrm{~nm}$, which was smaller than the averaged grain sizes of the samples from HEBM $(41.7 \mathrm{~nm})$ and planetary ball milling $(59.2 \mathrm{~nm})$. The estimated strain of the cryomilled powder was 0.0020 , which was also smaller than the strain of the HEBM sample (0.0028), and planetary ball milling (0.0030).

The cryomilled and planetary ball milled sample porosity was characterized with nitrogen porosimetry. The $\mathrm{N}_{2}$ adsorption-desorption curves in Figure S7a and S7b shows type II isotherm, which indicates both samples are mostly non-porous. Using the BarrettJoyner-Halenda $(\mathrm{BJH})$ method, the cumulative pore volume of the cryomilled and planetary ball milled sample were calculated to be $0.0044 \mathrm{~cm}^{3} / \mathrm{g}$ and $0.0058 \mathrm{~cm}^{3} / \mathrm{g}$, 
respectively, which also match the observed mostly dense particles from the SEM images for both samples. This shows that the cycling stability is not likely affected by the sample porosity.

To characterize the underlying nanostructures of the milled powder, a focused ion beam (FIB) was used to lift-out a lamella sample from the powder to use for cross-sectional STEM characterization. AC STEM high-angle annular dark field (HAADF) images (Figure 2c) showed mostly fiber-like fine-grained $\mathrm{SnSb}$ (bright region) reinforced with a carbon structure (dark region). After zooming in, the bright-field images (Figure 2d, 2e) showed majority of the $\mathrm{SnSb}$ grains are elongated and has width around $20 \mathrm{~nm}$. In addition, $\sim 3 \mathrm{~nm}$ thick multilayer graphene layers were observed between the grains. This indicated that cryomilling could exfoliate bulk graphite powder into nanometer-thick nanoplatelets and disperse this nano-graphite homogeneously within the $\mathrm{SnSb}$ grains. Based on Figure $2 \mathrm{c}$, the averaged carbon thickness with the cryomilled sample was $3.62 \pm 2.01 \mathrm{~nm}$, with the maximum measured carbon thickness being $11.04 \mathrm{~nm}$ (Figure S10). The atomic resolution HAADF image (Figure 2f) further shows an interplanar spacing of $0.217 \mathrm{~nm}$, which corresponds to the (012) orientation of $\mathrm{SnSb}$. The distribution of $\mathrm{SnSb}$ and carbon was further confirmed with STEM EDS mapping, as shown in Figure 3. Sn and Sb are relatively evenly distributed, as shown in the HAADF image in Figure 3a. The carbon EDS mapping (Figure 3b) confirms that the dark region in the HAADF image corresponds to the carbon matrix structure. 

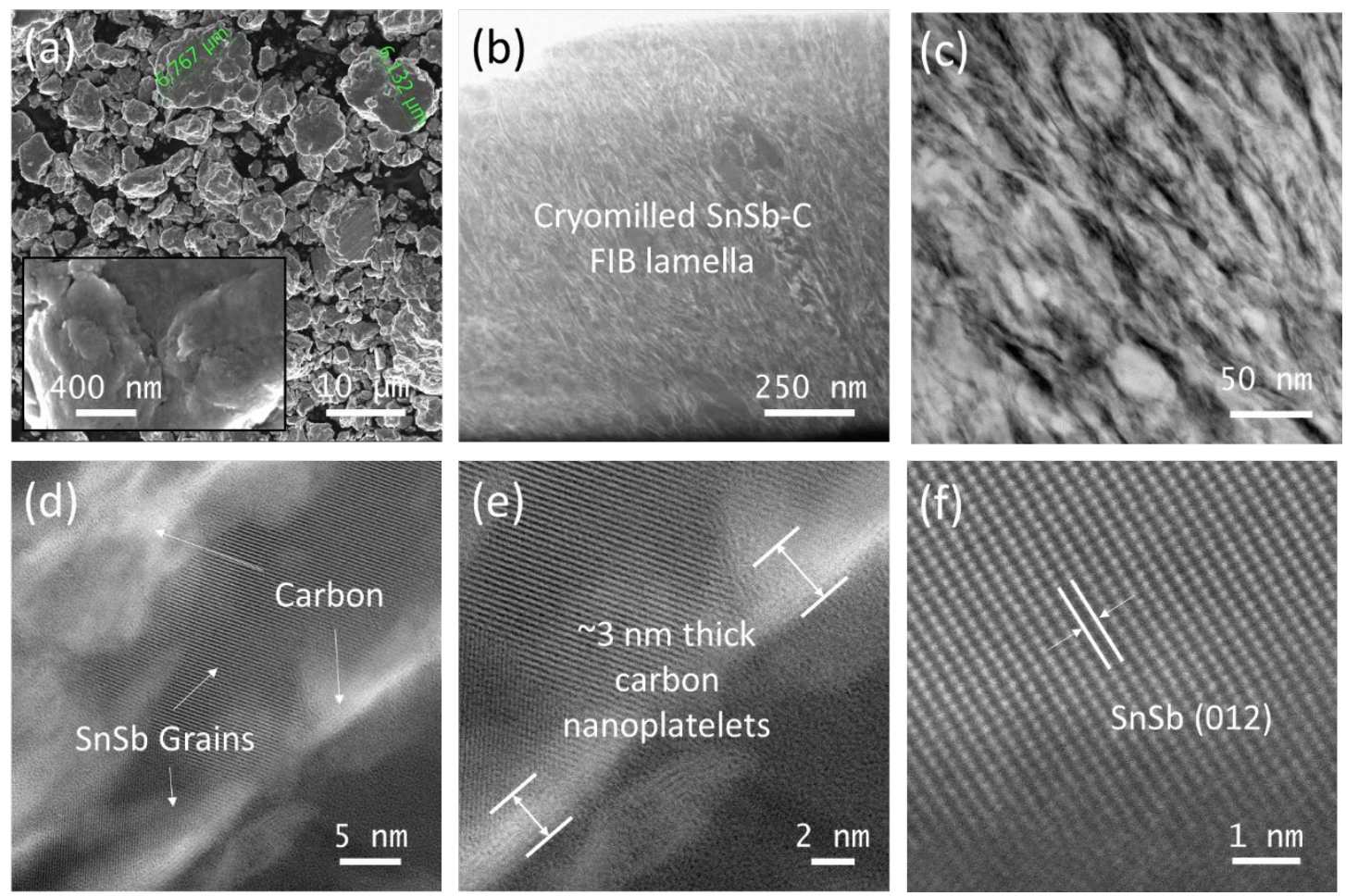

Figure 2. SEM and TEM micrographs of the cryomilled SnSb-C composite anode. (a) SEM image of the cryomilled SnSb-C. (b) low-mag bright field and (c) highmagnification STEM HAADF images revealing nanostructures in the cryomilled composite. (d) (e) high-magnification STEM bright-field images showing carbon nanoplatelets between the grains. (f) Atomic resolution STEM HAADF image of the SnSb grains.

$\mathrm{Sn}$ and Sb EDS mapping (Figure 3c,d) confirms the colocalization of $\mathrm{Sn}$ and $\mathrm{Sb}$, but also shows some $\mathrm{Sb}$-rich regions, in agreement with the small amount of residual $\mathrm{Sb}$ diffraction in figure 1d. The EDS spectrum fitting in Figure S4 showed that there are 4.0 at $\%$ C, 51.2 at $\% \mathrm{Sn}$, and $44.8 \mathrm{at} \% \mathrm{Sb}$, which can be well correlated to the designed composition. The small domain size of this material shows the feasibility of using cryomilling to fabricate high nanostructured carbon composite alloy anodes. It should be noted that for these cryomilled $\mathrm{SnSb}-\mathrm{C}$ composites, there still exists regions with higher $\mathrm{Sb}$ content (Figure 3d) and inhomogeneous grain sizes (Figure 2b), both of which are indications of insufficient mixing. Further fine-tuning of processing parameters is ongoing to optimize microstructure homogeneity. 
(a)
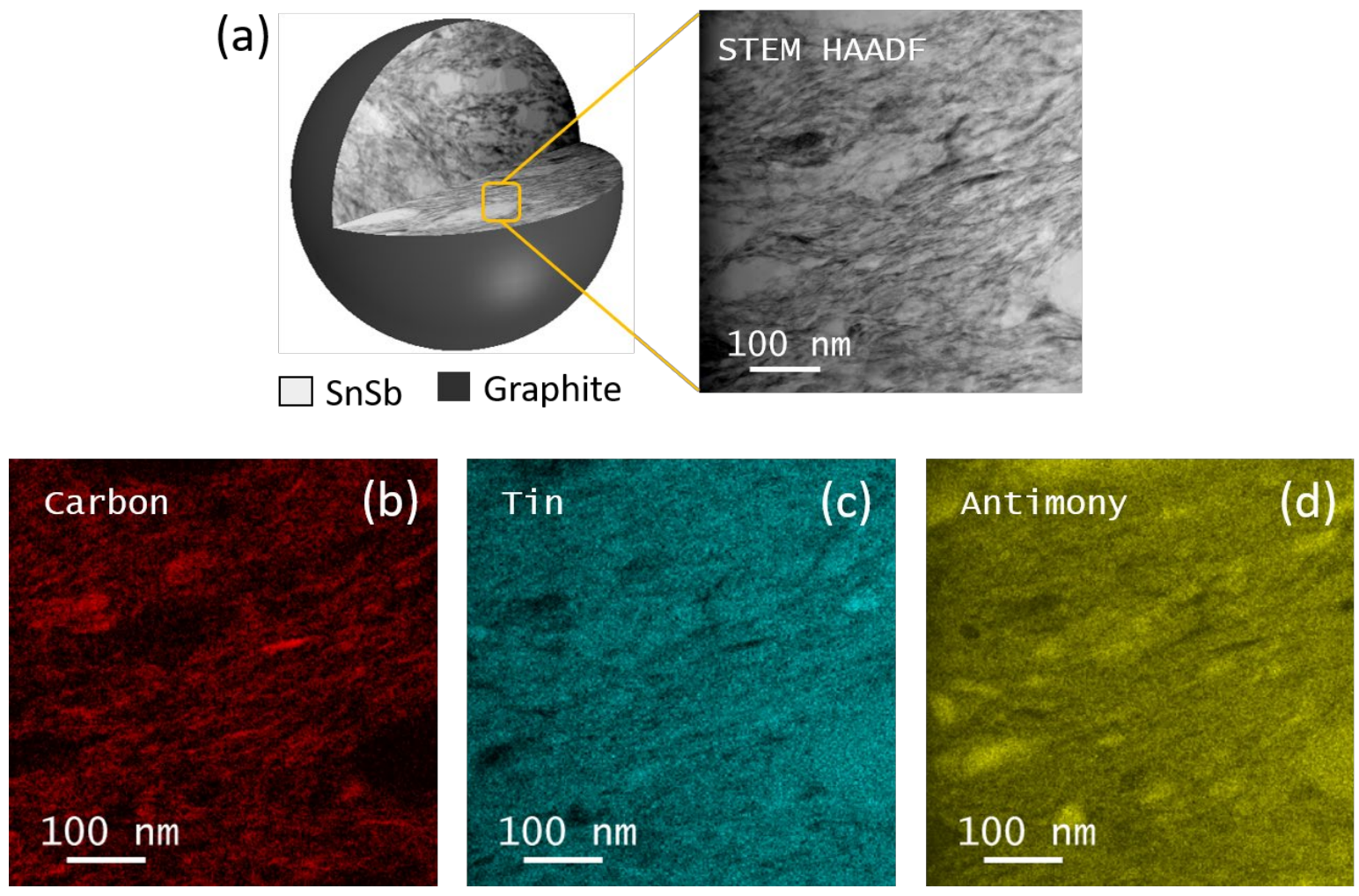

Figure 3. STEM image and EDS elemental maps of a cryomilled SnSb-C composite anode. (a) Schematic diagram and a STEM HAADF image of a cryomilled SnSb-C composite particle and the region where the EDS scan was performed. EDS elemental maps for (b) carbon, (c) tin, and (d) antimony.

To evaluate the potential of these materials as high energy density anodes, the electrochemical performance of the $\mathrm{SnSb}-\mathrm{C}$ composites synthesized with planetary ball milling and cryomilling was compared using galvanostatic cycling. The particle size of HEBM SnSb-C composite was greater than $100 \mu \mathrm{m}$; therefore, poor electrochemical performance was expected, in part due to inhomogeneous slurry mixing and tape casting. Additionally, large particles are known to easily fracture during cycling, ${ }^{14}$ and they can even penetrate the separator and cause battery shorting. Because of this, these samples were not studied further. The cycling performance of $\mathrm{SnSb}-\mathrm{C}$ composite made with $1 \mathrm{~h}$ and $4 \mathrm{~h}$ cryomilling was compared as shown in Figure S2b. The $4 \mathrm{~h}$ cryomilled composites showed higher coulombic efficiency (99.6\% vs. 97.5\%) and cycling stability, which likely benefit from the smaller grain size, formation of $\mathrm{SnSb}$ phase, and evenly distributed carbon matrix. The cryomilling and planetary ball milled samples have initial lithium capacity of $708 \mathrm{mAh} / \mathrm{g}$ and $697 \mathrm{mAh} / \mathrm{g}$, respectively (Figure 4b), which is lower than the $\mathrm{SnSb}$ 
theoretical capacity of $825 \mathrm{mAh} / \mathrm{g}$. The lower values are due to the higher voltage cutoff $(0.05-1.5 \mathrm{~V})$ used to prevent lithium plating. The cryomilled $\mathrm{SnSb}-\mathrm{C}$ showed a distinct voltage plateau during cycling (Figure $4 \mathrm{~b}$ ), indicating that most of the charge storage happens through well-defined alloying reactions. Figure 4a showed that the planetary milled SnSb-C composites lost $73 \%$ of capacity after 150 cycles with a coulombic efficiency that varied between 97.5 and $98.8 \%$. In comparison, the cryomilled $\mathrm{SnSb}-\mathrm{C}$ composite showed $84 \%$ capacity retention after 150 cycles with averaged coulombic efficiency of $99.6 \pm 0.3 \%$ (Figure $4 a$ ).
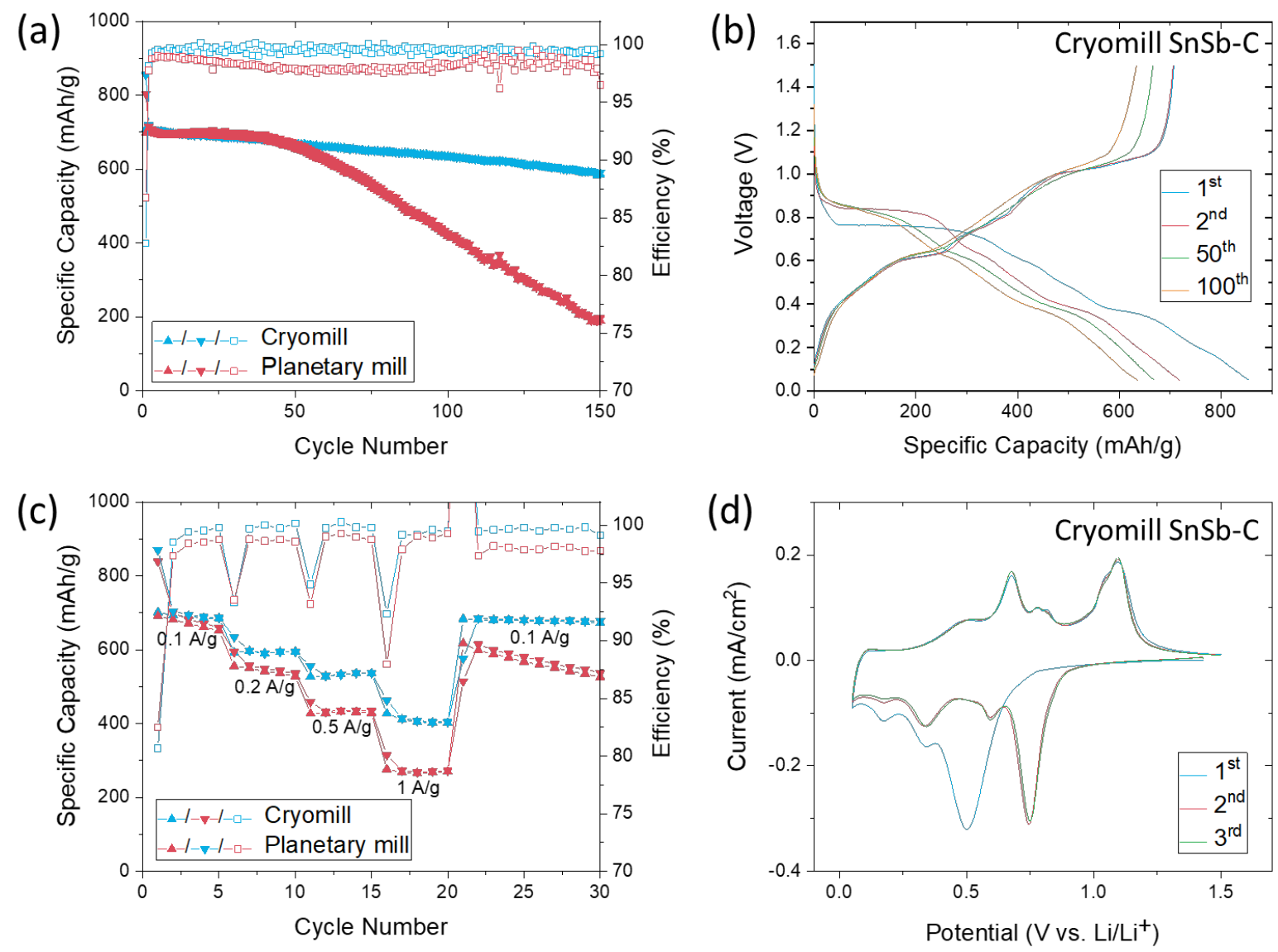

Figure 4. Electrochemical characterization of the cryomilled and planetary ball milled SnSb-C composite anodes. (a) Cycling stability for the cryomilled and planetary ball milled SnSb-C composite anodes cycled at $100 \mathrm{~mA} / \mathrm{g}$ between 0.05 $1.5 \mathrm{~V}$. (b) Voltage profiles of the cryomilled $\mathrm{SnSb}$-C composite anode for the $1^{\text {st }}, 2^{\text {nd }}$, $50^{\text {th }}$, and $100^{\text {th }}$ cycle at $100 \mathrm{~mA} / \mathrm{g}$. (c) Rate performance comparison of cryomilled and planetary ball milled samples. (d) Cyclic voltammetry of the cryomilled SnSbC composite anode at $0.1 \mathrm{mV} / \mathrm{s}$ between 0.05 and $1.5 \mathrm{~V}$. 
The rate capabilities of the cryomilled and planetary ball milled samples are shown in Figure $4 \mathrm{c}$. When the cycling current is increased to $200 \mathrm{~mA} / \mathrm{g}, 500 \mathrm{~mA} / \mathrm{g}$, and $1 \mathrm{~A} / \mathrm{g}$, the cryomilled sample demonstrated charge capacity of $598 \mathrm{mAh} / \mathrm{g}, 537 \mathrm{mAh} / \mathrm{g}$, and 415 $\mathrm{mAh} / \mathrm{g}$, respectively, which corresponds to $86 \%, 78 \%$, and $60 \%$ of the charge capacity at $100 \mathrm{~mA} / \mathrm{g}$, respectively. In contrast, the planetary ball milled composite only showed charge capacity of $541 \mathrm{mAh} / \mathrm{g}, 428 \mathrm{mAh} / \mathrm{g}, 266 \mathrm{mAh} / \mathrm{g}$, respectively, which corresponds to $77 \%, 61 \%, 38 \%$ of the charge capacity at $100 \mathrm{~mA} / \mathrm{g}$. When the current density was returned to $100 \mathrm{~mA} / \mathrm{g}$ after being subjected to currents as high as $1 \mathrm{~A} / \mathrm{g}$, the lower specific capacity values suggest possible electrode microstructure damage after high rate cycling. To further evaluate the cryomilled SnSb-C electrode kinetics, cyclic voltammetry (CV) was also conducted (Figure 4d). The response correlates well to the galvanostatic cycling results. The first $\mathrm{CV}$ cycle showed a reduction peak at $0.5 \mathrm{~V}$, which can be assigned to the formation of $\mathrm{Li}_{3} \mathrm{Sb}$ phase and solid electrolyte interface (SEI) layer ${ }^{27,30}$. The remaining reduction peaks from $0.4 \mathrm{~V}$ to $0.05 \mathrm{~V}$ could be labeled with the formation of Li-Sn intermetallic including $\mathrm{Li}_{2} \mathrm{Sn}_{5}$, LiSn and $\mathrm{Li}_{4} .4 \mathrm{Sn}^{14}$. At Cycle 2 and 3, the change in the first reduction peak potential corresponds to the phase separation of the $\mathrm{Sb}$ and $\mathrm{Sn}$. The redox peak current densities are mostly unchanged for the $2^{\text {nd }}$ and $3^{\text {rd }} \mathrm{CV}$ cycle, thereby indicating good cycling stability of the cryomilled SnSb-C composite electrode.

To evaluate the effectiveness of the nanostructure on alleviating crack formation, the morphology of the composites was evaluated using SEM for the first lithiation and after 20 cycles (Figure 5). After the initial lithiation, minor cracks could be found for the large particles $(>5 \mu \mathrm{m})$ in the planetary ball milled sample shown in Figure 5e and Figure S6e, but not in the cryo-milled sample. After 20 cycles, severe cracking and complete particle fracture were commonly found in single-particle SEM images throughout the electrode for the planetary ball milled sample, as shown in Figure 5f, and at lower magnification in Figure S6f. Severe particle fracture exposes fresh surface which can cause excessive SEI formation with electrolyte, which explains the observed low Coulombic efficiency and fast capacity fade for the planetary ball milled composite. 

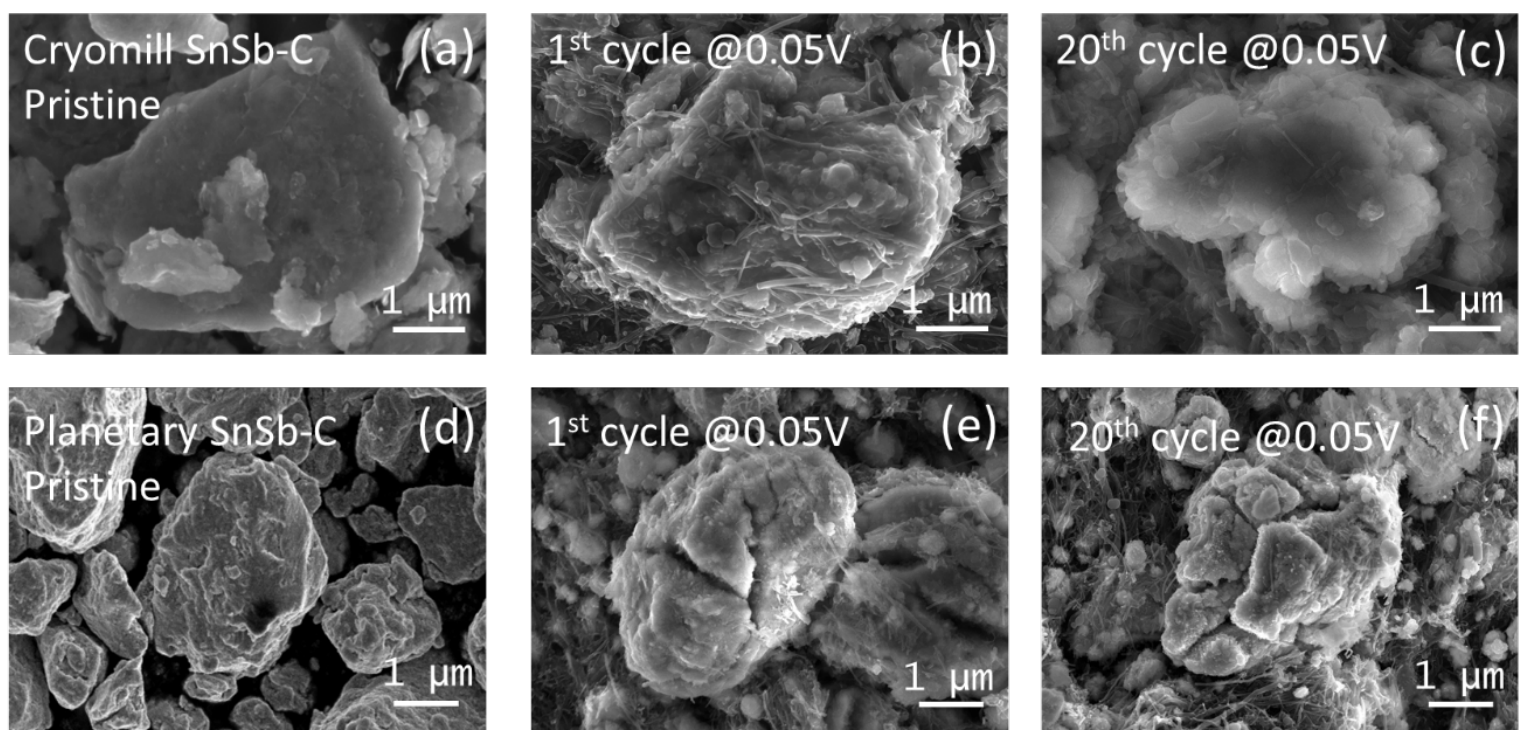

Figure 5. Comparison of the changes in morphologies upon cycling for cryomilled and planetary ball milled SnSb-C composite anodes. (a) The pristine cryomilled SnSb-C composite anode. Ex-situ SEM of cryomilled SnSb-C (b) after initial lithiation and (c) after 20 cycles. (d) The pristine planetary ball milled SnSb-C composite anode. Ex-situ SEM of planetary ball milled SnSb-C (e) after initial lithiation and (f) after 20 cycles. Cracking is observed in the planetary milled sample, but not in the cryo-milled material. Low-magnification SEM images can be found in Figure S5 and Figure S6.

For the cryomilled sample, surface bulges were observed on particle after initial lithiation, indicating volume expansion from the alloying reaction. However, no obvious cracking could be easily spotted in the SEM images (Figure 5b and Figure S5e), which demonstrates the effectiveness of the carbon matrix structure and the refined grain size. When the cryomilled composite was cycled for 20 cycles, the particle surface became noticeably rough (Figure 5c) and some minor surface cracks could be spotted for the larger particles (Figure S5f). Nevertheless, most particles still maintain their shapes and no complete fracture could be observed. This improved post-cycling morphology was consistent with the improved electrochemical stability of the cryomilled SnSb-C composite.

As previous reviews have pointed out, the volumetric energy density of many alloy type carbon composite anodes can be limited due to the large volume of low-density carbon and internal porosity. ${ }^{14,18}$ The present research demonstrates that cryomilling can be utilized for facile fabrication of high energy density anodes. The cryomilled SnSb-C composite is mostly non-porous $\left(0.0044 \mathrm{~cm}^{3} / \mathrm{g}\right.$ porosity $)$, and it has a gravimetric capacity 
of $669 \mathrm{mAh} / \mathrm{g}$ after $50 \mathrm{cycles}$ at $100 \mathrm{~mA} / \mathrm{g}$. Using the density of graphite $\left(2.2 \mathrm{~g} / \mathrm{cm}^{3}\right)$ and fully lithiated $\mathrm{SnSb}\left(2.78 \mathrm{~g} / \mathrm{cm}^{3}\right)$, the composite demonstrates a volumetric capacity $q_{R}^{-}$of $1842 \mathrm{Ah} / \mathrm{L}$, which shows significant improvement compared to a graphite anode (756 $\mathrm{Ah} / \mathrm{L}$ ). For energy storage applications in portable electronics and electric vehicles, it is more important to compare the improvements on full cell energy density. ${ }^{14,31}$ Active material porosity, average voltage, irreversible capacity, and coulombic efficiency all have significant impacts on cell energy density and performance.

By adopting the cell-based model proposed by Obrovac et al., ${ }^{14}$ the stack energy can be calculated by the assumption that the anode electrode contains 70 vol\% SnSb-C, and the anode irreversible capacity matches that of the cathode. $\mathrm{LiCoO}_{2}$ was selected as the baseline cathode that has a reversible volumetric capacity $q_{R}^{+}$of $530 \mathrm{Ah} / \mathrm{L}$, and an average voltage $V_{\text {avg }}^{+}$of $3.9 \mathrm{~V}$. The $\mathrm{N} / \mathrm{P}$ ratio (capacity ratio of the negative and positive electrode) was set to be 1.1. The cryomilled SnSb-C composite has an average voltage $V_{\text {avg }}^{-}$of $0.75 \mathrm{~V}$. Using these data and assumptions, the stack energy $U_{R}$ can be calculated to be $855 \mathrm{Wh} / \mathrm{L}$ based on the following equation: ${ }^{14}$

$$
U_{R}=\frac{2 q_{R}^{+} t^{+}}{t_{c c}^{+}+t_{c c}^{-}+2 t_{s}+2 t^{+}\left[1+\frac{q_{R}^{+}}{q_{R}^{(}}\left(\frac{N}{P}\right)\right]}\left(V_{\text {avg }}^{+}-V_{\text {avg }}^{-}\right),
$$

where the cathode current collector thickness $t_{c c}^{+}$and anode current collector thickness $t_{c c}^{-}$ were set to $15 \mu \mathrm{m}$, the separator thickness $t_{s}$ was set to $20 \mu \mathrm{m}$, and the cathode electrode thickness $t^{+}$was set to $55 \mu \mathrm{m}$. Based on this full cell model, an $18 \%$ increase in the stack level volumetric energy density can be obtained with the cryomilled SnSb-C composite compared to the baseline $\mathrm{LCO} /$ graphite cell $(726 \mathrm{Wh} / \mathrm{L}) \cdot{ }^{14}$ Note that the volumetric energy density of the modeled cell with cryomilled $\mathrm{SnSb}-\mathrm{C}$ anode is likely to be higher since $\sim 250 \%$ volume expansion was assumed based on the theoretical density differences between $\mathrm{SnSb}$ and fully-lithiated $\mathrm{SnSb}$ to prevent overestimation. A more reliable estimation of the anode volume expansion and energy density will be conducted in the future using in-situ transmission X-ray tomography (TXM) studies during electrochemical cycling. ${ }^{28,32}$

Based on the structural and electrochemical characterization, the major improvement in cycling stability of the $\mathrm{SnSb}-\mathrm{C}$ composite can be attributed to the nanostructures from 
the cryomilling process, namely the refined grain size and the well-dispersed graphite within the $\mathrm{SnSb}$. Fecht et al. proposed an empirical description of the microstructure development during ball milling in three stages: ${ }^{33} 1$ ) localized deformation occurs in shear bands (the region with a high dislocation density), 2) after a certain strain level is reached, nanometer-sized sub-grains form via dislocation recombination, and 3) randomly oriented single-crystalline grains recrystallize from the sub-grain structure. The competing process of dislocation generation during plastic deformation and grain recovery by thermal effects determines the minimum grain size achievable of the milling process. ${ }^{34}$ At cryogenic temperature, the recovery, recrystallization, and grain growth can be limited. Therefore, a fine-grained structure can be achieved with shorter milling time. ${ }^{22,35}$ A theoretical dislocation model for milling minimum grain sizes also suggests a decrease in grain size with lower milling temperature. ${ }^{36} \mathrm{SnSb}$ sample without carbon addition was fabricated via HEBM and cryomill, as shown Figure S8. Using W-H analysis, the grain size of the cryomilled $\mathrm{SnSb}$ was estimated to be $43 \mathrm{~nm}$ with a strain of 0.0023 . In comparison, the grain size of the HEBM SnSb was estimated to be $99 \mathrm{~nm}$ with a strain of 0.0034 . These results further showed a decrease in grain size can be achieved with lower milling temperature under the same milling time.

In addition to allowing for the formation of nanoscale grains, cryomilling has another advantage when it comes to dispersing nanoscale carbon. Due to its high specific surface area and strong van der Waals interactions, both multilayered graphene and carbon nanotubes tend to stick together and form agglomerates, making them hard to disperse in the matrix structure. ${ }^{37,38}$ Cryomilling has been shown to be an effective method to exfoliate graphite flakes into nanoplatelets ${ }^{25}$ and prevent agglomeration ${ }^{26,39}$ in nanocomposites. Various research groups have fabricated CNT reinforced aluminum matrix composites with good CNT dispersity and minimal sidewall defects using cryo-milling. ${ }^{24,40,41}$ Similarly, in this work, the initial micron-sized graphite powder was exfoliated into nanoplatelets and evenly dispersed between the SnSb grains. Raman spectroscopy was also utilized to study the carbon structure of the samples fabricated from HEBM and cryomill, as shown in Figure S9. The 2D band of the HEBM sample has weak intensity due to the disordered structure. ${ }^{42,43}$ The ratio of $\mathrm{D}$ and $\mathrm{G}$ band can be used to determine the structural defects in carbon materials. ${ }^{44} \mathrm{I}_{\mathrm{D}} / \mathrm{I}_{\mathrm{G}}$ of the cryomilled sample was 0.82 , which was much lower than 
the ratio of the HEBM sample (1.35). This showcased cryomill can reduce defects formation during milling process, which also correlates well with previous studies. ${ }^{24,39,45}$ Various forms of carbons, including graphite, graphene, CNT, and amorphous carbons are being widely used with high volume change anodes due to their ability to buffer volume changes using their internal void space or by creating wrinkled structure. ${ }^{14,18}$ In this work, the well-dispersed nanoplatelets may also suppress grain growth and matrix phase coarsening ( $\mathrm{Li} 3 \mathrm{Sb})$ via grain boundary pinning. ${ }^{22,26}$

\section{Conclusions}

We have developed a facile synthesis method using cryogenic milling to produce stable, high energy density anode materials. SnSb-C composites were chosen as a model system to demonstrate the improvements on nanostructure and cycling stability. The cryomilled $\mathrm{SnSb}-\mathrm{C}$ showed a specific capacity of $708 \mathrm{mAh} / \mathrm{g}$ and an initial Coulombic efficiency of $83 \%$. After the first cycle, the anode showed an average Coulombic efficiency of $99.6 \pm$ $0.3 \%$ and capacity retention of $90 \%$ over 100 cycles. Moreover, the composite anode has a reversible volumetric capacity of $1842 \mathrm{Ah} / \mathrm{L}$, and an expected full cell stacking volumetric energy density is $855 \mathrm{Wh} / \mathrm{L}$ if $\mathrm{LiCoO}_{2}$ was used as the cathode. This corresponds to an $18 \%$ increase compared to a baseline $\mathrm{LiCoO}_{2} /$ graphite cell. Based on STEM and post-cycling SEM analysis, the nanometer scale grain size and well-dispersed carbon matrix structure appears to reduce volume expansion and particle cracking during cycling. This work demonstrates the application of cryomilling on battery electrode materials and shows improved cycle life compared with materials obtained using conventional ball mill routes. Cryomilling can potentially become a general method for improving other battery electrode materials, thereby providing a pathway for developing high-performance energy storage systems.

\section{- ASSOCIATED CONTENT}

\section{Supporting Information}

The Supporting Information is available free of charge on the ACS Publications website. The supporting information includes SEM, XRD and cycling performance comparison of the cryomilled $\mathrm{SnSb}-\mathrm{C}$ composite morphology under different milling time; SEM of the unmixed graphite flakes found in the 8 hour planetary ball milled SnSb-C 
composite powder; STEM EDS spectrum fitting of the cryomilled SnSb-C sample; zoomed out post-cycling SEM images of cryomilled sample and planetary ball milled sample; and nitrogen porosimetry measurements of the cryomilled and planetary ball milled samples.

\section{- AUTHOR INFORMATION}

\section{Corresponding Author}

E-mail: jluo@alum.mit.edu

\section{- ACKNOWLEDGEMENTS}

This work was supported as part of the Center for Synthetic Control Across Length-scales for Advancing Rechargeables (SCALAR), an Energy Frontier Research Center funded by the United States Department of Energy, Office of Science, Basic Energy Sciences under Award No. DESC0019381.

A patent was filed for this work through the UCSD Office of Innovation and Commercialization. 
(a)

High-energy Ball Mill

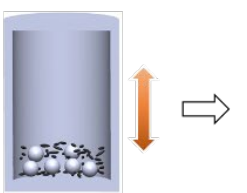

(b) Cryogenic
Ball Mill

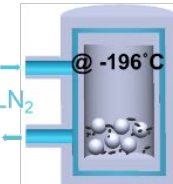

(c) Planetary Ball Mill

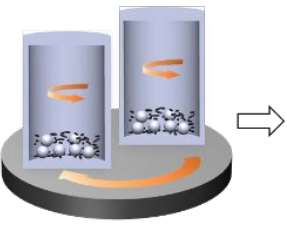

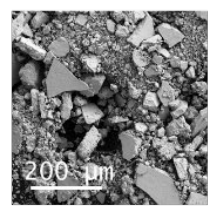
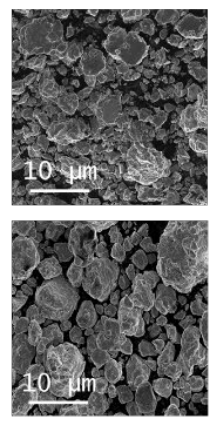

(d)

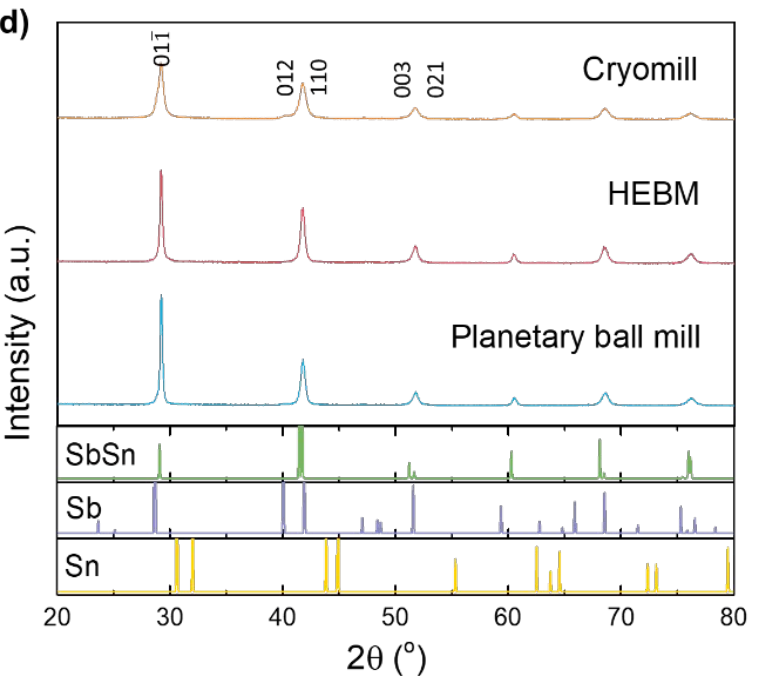

Figure 1. Synthesis method and SEM images of mechanical alloyed SnSb-C composite anodes fabricated through (a) high-energy ball mill, (b) cryogenic ball mill, and (c) planetary ball mill. (b) X-ray diffraction patterns comparing SnSb-C composite anodes synthesized through these three different mechanical methods. All methods produce $\mathrm{SbSn}$, but the degree of crystallinity, as evidenced by the diffraction peak widths, varies dramatically between methods. 

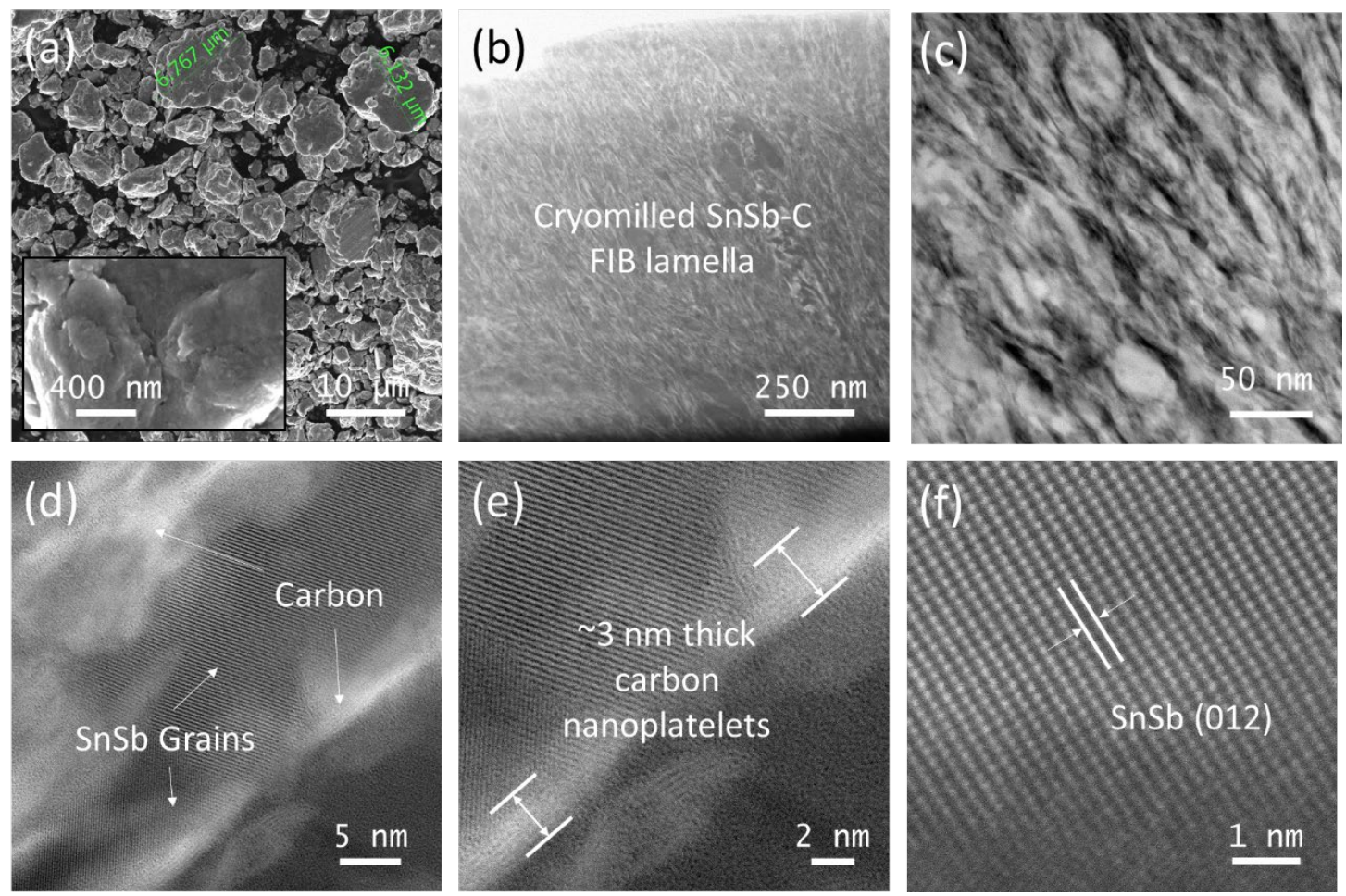

Figure 2. SEM and TEM micrographs of the cryomilled SnSb-C composite anode. (a) SEM image of the cryomilled SnSb-C. (b) low-mag bright field and (c) highmagnification STEM HAADF images revealing nanostructures in the cryomilled composite. (d) (e) high-magnification STEM bright-field images showing carbon nanoplatelets between the grains. (f) Atomic resolution STEM HAADF image of the $\mathrm{SnSb}$ grains. 
(a)
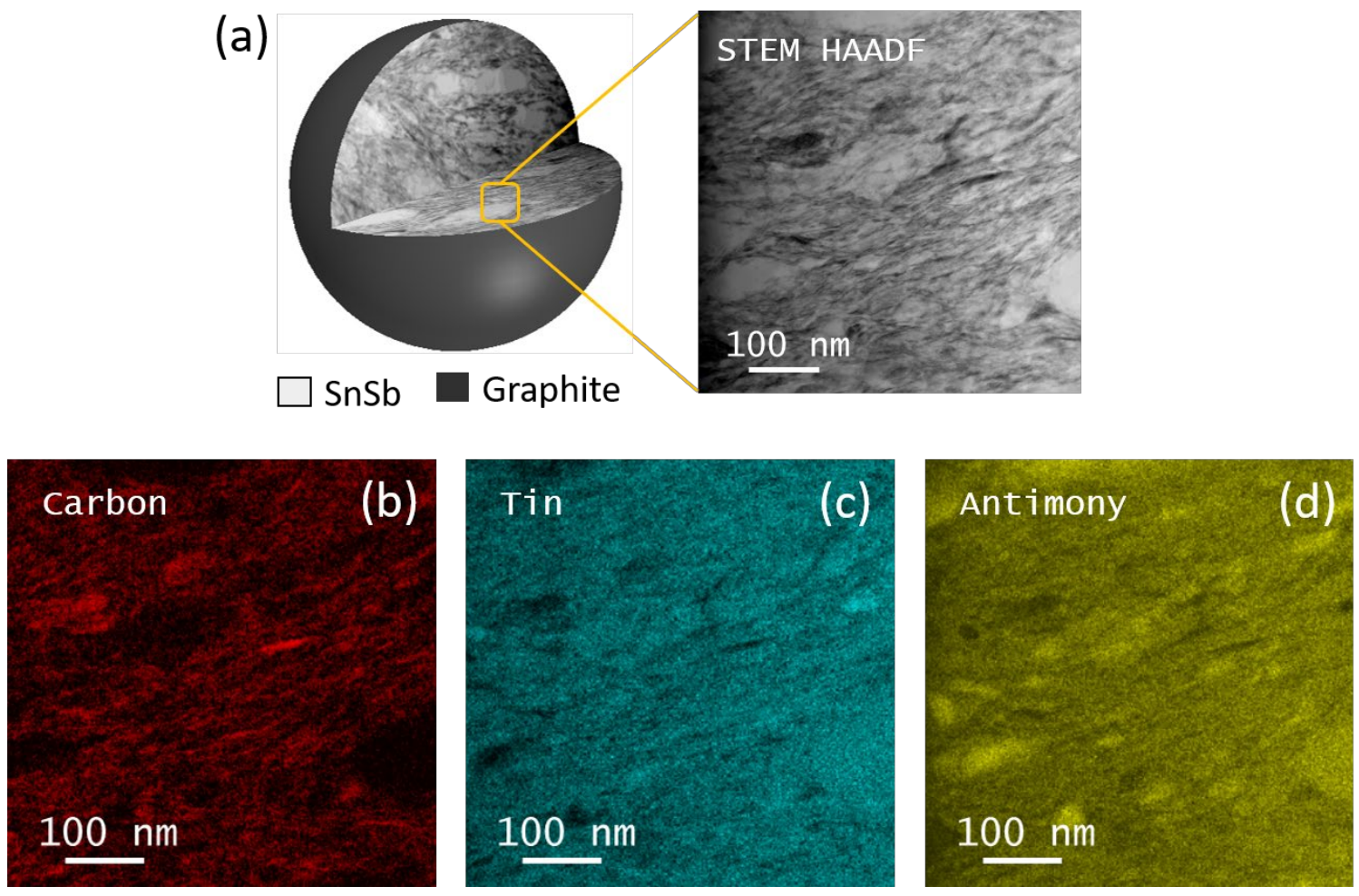

Figure 3. STEM image and EDS elemental maps of a cryomilled $\mathrm{SnSb}-\mathrm{C}$ composite anode. (a) Schematic diagram and a STEM HAADF image of a cryomilled SnSb-C composite particle and the region where the EDS scan was performed. EDS elemental maps for (b) carbon, (c) tin, and (d) antimony. 
(a)

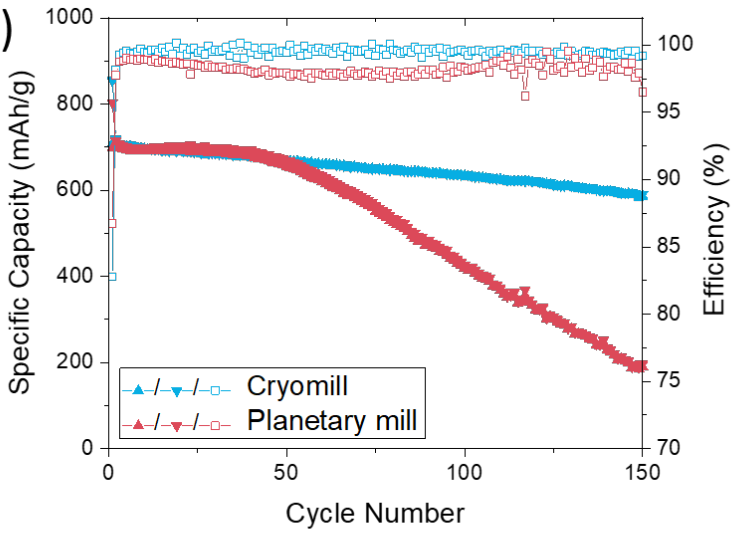

(c)

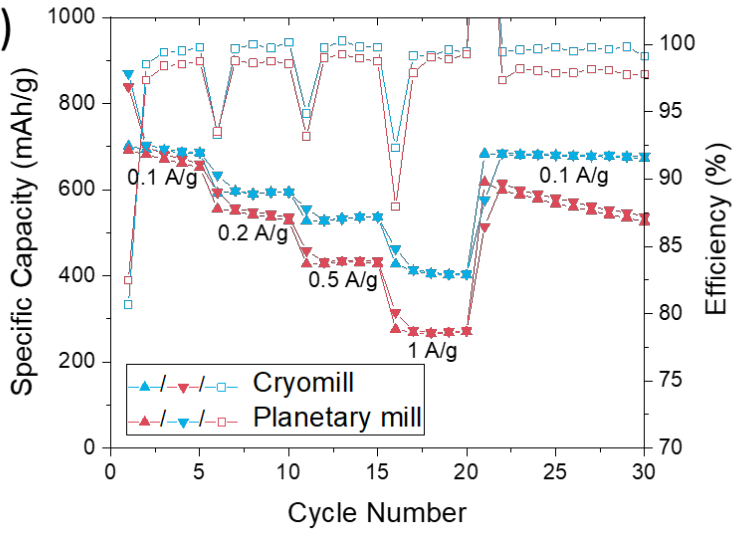

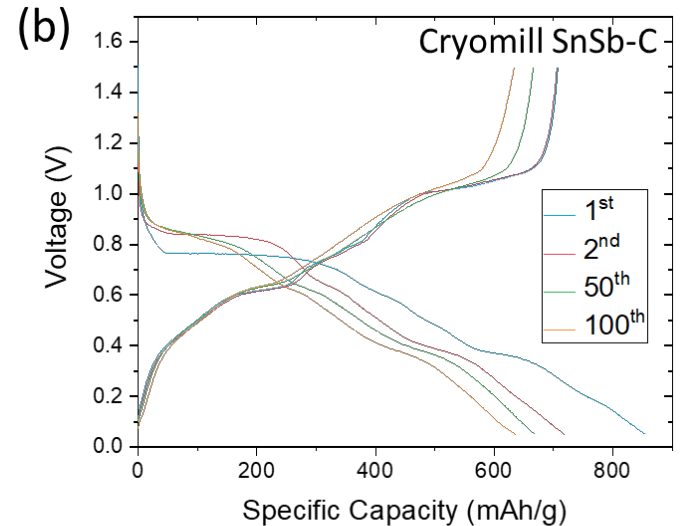

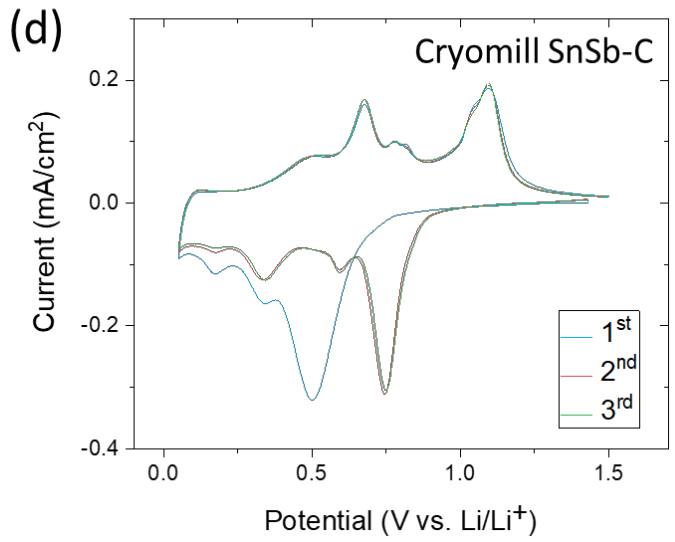

Figure 4. Electrochemical characterization of the cryomilled and planetary ball milled SnSb-C composite anodes. (a) Cycling stability for the cryomilled and planetary ball milled SnSb-C composite anodes cycled at $100 \mathrm{~mA} / \mathrm{g}$ between $0.05-1.5 \mathrm{~V}$. (b) Voltage profiles of the cryomilled SnSb-C composite anode for the $1^{\text {st }}, 2^{\text {nd }}, 50^{\text {th }}$, and $100^{\text {th }}$ cycle at $100 \mathrm{~mA} / \mathrm{g}$. (c) Rate performance comparison of cryomilled and planetary ball milled samples. (d) Cyclic voltammetry of the cryomilled SnSb-C composite anode at $0.1 \mathrm{mV} / \mathrm{s}$ between 0.05 and $1.5 \mathrm{~V}$. 

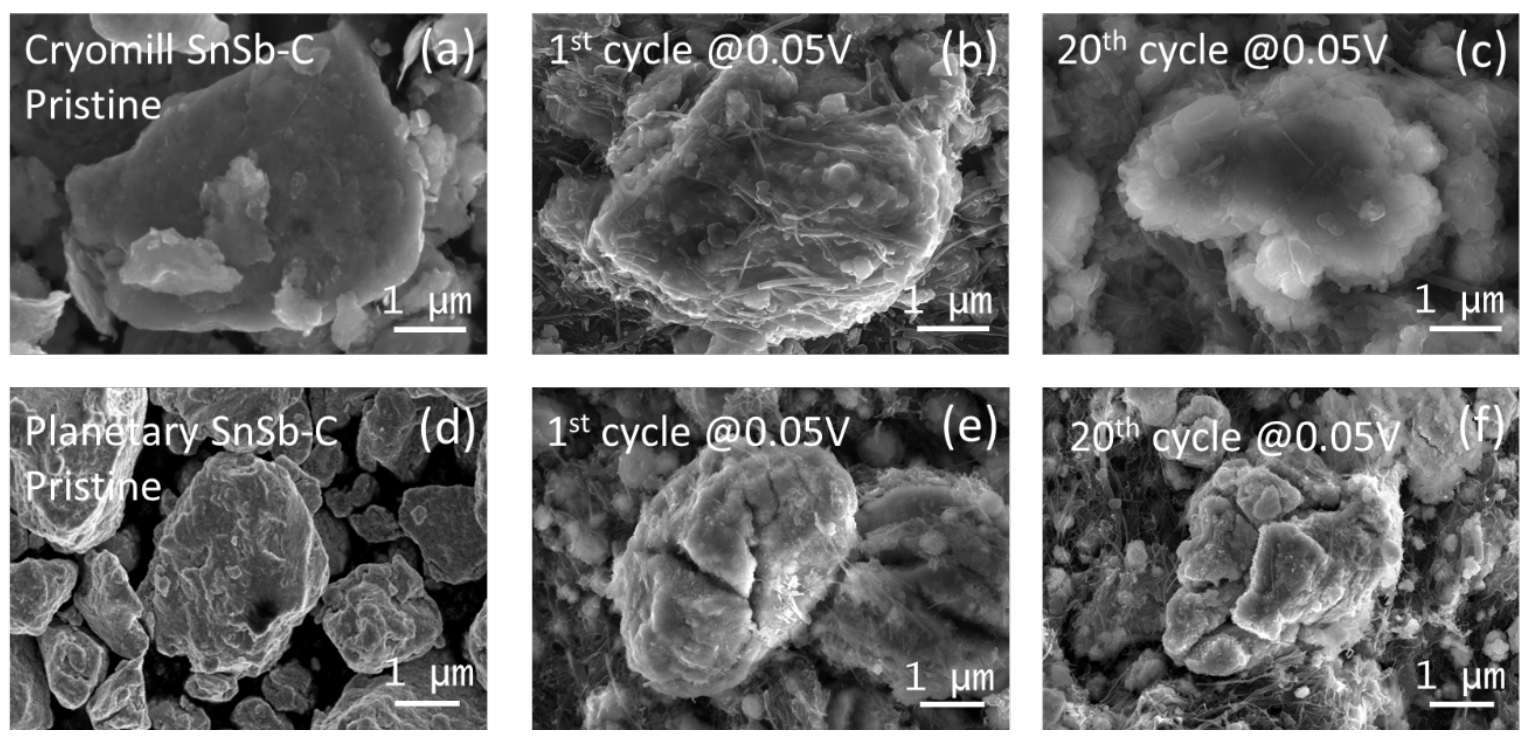

Figure 5. Comparison of the changes in morphologies upon cycling for cryomilled and planetary ball milled SnSb-C composite anodes. (a) The pristine cryomilled SnSb-C composite anode. Ex-situ SEM of cryomilled SnSb-C (b) after initial lithiation and (c) after 20 cycles. (d) The pristine planetary ball milled SnSb-C composite anode. Ex-situ SEM of planetary ball milled SnSb-C (e) after initial lithiation and (f) after 20 cycles. Cracking is observed in the planetary milled sample, but not in the cryo-milled material. Low-magnification SEM images can be found in Figure S5 and Figure S6. 


\section{References}

(1) Endo, M.; Kim, C.; Nishimura, K.; Fujino, T.; Miyashita, K. Recent Development of Carbon Materials for Li Ion Batteries. Carbon N. Y. 2000, 38 (2), 183-197. https://doi.org/10.1016/S0008-6223(99)00141-4.

(2) Cook, J. B.; Detsi, E.; Liu, Y.; Liang, Y. L.; Kim, H. S.; Petrissans, X.; Dunn, B.; Tolbert, S. H. Nanoporous Tin with a Granular Hierarchical Ligament Morphology as a Highly Stable Li-Ion Battery Anode. ACS Appl. Mater. Interfaces 2017, 9 (1), 293-303. https://doi.org/10.1021/acsami.6b09014.

(3) Detsi, E.; Petrissans, X.; Yan, Y.; Cook, J. B.; Deng, Z.; Liang, Y. L.; Dunn, B.; Tolbert, S. H. Tuning Ligament Shape in Dealloyed Nanoporous Tin and the Impact of Nanoscale Morphology on Its Applications in Na-Ion Alloy Battery Anodes. Phys. Rev. Mater. 2018, 2 (5), 32-37.

https://doi.org/10.1103/PhysRevMaterials.2.055404.

(4) Cook, J. B.; Lin, T. C.; Detsi, E.; Weker, J. N.; Tolbert, S. H. Using X-Ray Microscopy to Understand How Nanoporous Materials Can Be Used to Reduce the Large Volume Change in Alloy Anodes. Nano Lett. 2017, 17 (2), 870-877. https://doi.org/10.1021/acs.nanolett.6b04181.

(5) Dong, Z.; Zhang, R.; Ji, D.; Chernova, N. A.; Karki, K.; Sallis, S.; Piper, L.; Stanley Whittingham, M. The Anode Challenge for Lithium-Ion Batteries: A Mechanochemically Synthesized Sn-Fe-C Composite Anode Surpasses Graphitic Carbon. Adv. Sci. 2016, 3 (4), 1-8. https://doi.org/10.1002/advs.201500229.

(6) Ferguson, P. P.; Le, D. B.; Todd, A. D. W.; Martine, M. L.; Trussler, S.; Obrovac, M. N.; Dahn, J. R. Nanostructured Sn30Co30C40 Alloys for Lithium-Ion Battery Negative Electrodes Prepared by Horizontal Roller Milling. J. Alloys Compd. 2014, 595, 138-141. https://doi.org/10.1016/j.jallcom.2014.01.159.

(7) Park, A. R.; Park, C. M. Cubic Crystal-Structured SnTe for Superior Li- and NaIon Battery Anodes. ACS Nano 2017, 11 (6), 6074-6084. https://doi.org/10.1021/acsnano.7b02039.

(8) Park, M. G.; Lee, D. H.; Jung, H.; Choi, J. H.; Park, C. M. Sn-Based Nanocomposite for Li-Ion Battery Anode with High Energy Density, Rate Capability, and Reversibility. ACS Nano 2018, 12 (3), 2955-2967. https://doi.org/10.1021/acsnano.8b00586.

(9) Lee, D. H.; Park, C. M. Tin Selenides with Layered Crystal Structures for Li-Ion Batteries: Interesting Phase Change Mechanisms and Outstanding Electrochemical Behaviors. ACS Appl. Mater. Interfaces 2017, 9 (18), 15439-15448. https://doi.org/10.1021/acsami.7b01829.

(10) Liu, N.; Lu, Z.; Zhao, J.; Mcdowell, M. T.; Lee, H. W.; Zhao, W.; Cui, Y. A Pomegranate-Inspired Nanoscale Design for Large-Volume-Change Lithium Battery Anodes. Nat. Nanotechnol. 2014, 9 (3), 187-192. https://doi.org/10.1038/nnano.2014.6. 
(11) Wang, B.; Li, X.; Zhang, X.; Luo, B.; Zhang, Y.; Zhi, L. Contact-Engineered and Void-Involved Silicon/Carbon Nanohybrids as Lithium-Ion-Battery Anodes. $A d v$. Mater. 2013, 25 (26), 3560-3565. https://doi.org/10.1002/adma.201300844.

(12) Kim, H.; Cho, J. Superior Lithium Electroactive Mesoporous Si@Carbon CoreShell Nanowires for Lithium Battery Anode Material. Nano Lett. 2008, 8 (11), 3688-3691. https://doi.org/10.1021/n1801853x.

(13) Inoue, H.; Mizutani, S.; Ishihara, H.; Hatake, S. 214th ECS Meeting, 2007; Abstract \#1160.

(14) Obrovac, M. N.; Chevrier, V. L. Alloy Negative Electrodes for Li-Ion Batteries. Chem. Rev. 2014, 114 (23), 11444-11502. https://doi.org/10.1021/cr500207g.

(15) Fan, Q.; Chupas, P. J.; Whittingham, M. S. Characterization of Amorphous and Crystalline Tin-Cobalt Anodes. Electrochem. Solid-State Lett. 2007, 10 (12), 274 278. https://doi.org/10.1149/1.2789418.

(16) Ferguson, P. P.; Martine, M. L.; George, A. E.; Dahn, J. R. Studies of TinTransition Metal-Carbon and Tin-Cobalt-Transition Metal-Carbon Negative Electrode Materials Prepared by Mechanical Attrition. J. Power Sources 2009, 194 (2), 794-800. https://doi.org/10.1016/j.jpowsour.2009.05.031.

(17) Suryanarayana, C. Mechanical Alloying and Milling. Prog. Mater. Sci. 2001, 46 (1-2), 1-184. https://doi.org/10.1016/S0079-6425(99)00010-9.

(18) Park, C. M.; Kim, J. H.; Kim, H.; Sohn, H. J. Li-Alloy Based Anode Materials for Li Secondary Batteries. Chem. Soc. Rev. 2010, 39 (8), 3115-3141. https://doi.org/10.1039/b919877f.

(19) Dhital, S.; Shrestha, A. K.; Gidley, M. J. Effect of Cryo-Milling on Starches: Functionality and Digestibility. Food Hydrocoll. 2010, 24 (2-3), 152-163. https://doi.org/10.1016/j.foodhyd.2009.08.013.

(20) Devi, A. F.; Fibrianto, K.; Torley, P. J.; Bhandari, B. Physical Properties of Cryomilled Rice Starch. J. Cereal Sci. 2009, 49 (2), 278-284. https://doi.org/10.1016/j.jcs.2008.11.005.

(21) Loick, C.; Gartz, D.; Wattebled, L.; Harren, J. Process for Producing Improved Absorbent Polymers by Means of Cryogenic Grinding. Google Patents 2014.

(22) Witkin, D. B.; Lavernia, E. J. Synthesis and Mechanical Behavior of Nanostructured Materials via Cryomilling. Prog. Mater. Sci. 2006, 51 (1), 1-60. https://doi.org/10.1016/j.pmatsci.2005.04.004.

(23) Kumar, N.; Biswas, K. Cryomilling: An Environment Friendly Approach of Preparation Large Quantity Ultra Refined Pure Aluminium Nanoparticles. J. Mater. Res. Technol. 2019, 8 (1), 63-74. https://doi.org/10.1016/j.jmrt.2017.05.017.

(24) He, T.; He, X.; Tang, P.; Chu, D.; Wang, X.; Li, P. The Use of Cryogenic Milling to Prepare High Performance A12009 Matrix Composites with Dispersive Carbon 
Nanotubes. Mater. Des. 2017, 114, 373-382.

https://doi.org/10.1016/j.matdes.2016.11.008.

(25) Hubert, P. J.; Kathiresan, K.; Wakabayashi, K. Filler Exfoliation and Dispersion in Polypropylene/as-Received Graphite Nanocomposites via Cryogenic Milling. Polym. Eng. Sci. 2011, 51 (11), 2273-2281. https://doi.org/10.1002/pen.22001.

(26) Li, J. L.; Xiong, Y. C.; Wang, X. D.; Yan, S. J.; Yang, C.; He, W. W.; Chen, J. Z.; Wang, S. Q.; Zhang, X. Y.; Dai, S. L. Microstructure and Tensile Properties of Bulk Nanostructured Aluminum/Graphene Composites Prepared via Cryomilling. Mater. Sci. Eng. A 2015, 626, 400-405. https://doi.org/10.1016/j.msea.2014.12.102.

(27) Antitomaso, P.; Fraisse, B.; Stievano, L.; Biscaglia, S.; Aymé-Perrot, D.; Girard, P.; Sougrati, M. T.; Monconduit, L. SnSb Electrodes for Li-Ion Batteries: The Electrochemical Mechanism and Capacity Fading Origins Elucidated by Using Operando Techniques. J. Mater. Chem. A 2017, 5 (14), 6546-6555. https://doi.org/10.1039/C6TA10138K.

(28) Chao, S. C.; Song, Y. F.; Wang, C. C.; Sheu, H. S.; Wu, H. C.; Wu, N. L. Study on Microstructural Deformation of Working Sn and SnSb Anode Particles for Li-Ion Batteries by in Situ Transmission X-Ray Microscopy. J. Phys. Chem. C 2011, 115 (44), 22040-22047. https://doi.org/10.1021/jp206829q.

(29) Yang, J.; Winter, M.; Besenhard, J. O. Small Particle Size Multiphase Li-Alloy Anodes for Lithium-Ionbatteries. Solid state ionics 1996, 90 (1-4), 281-287.

(30) Seo, J. U.; Park, C. M. Nanostructured $\mathrm{SnSb} / \mathrm{MOx}(\mathrm{M}=\mathrm{Al}$ or $\mathrm{Mg}$ )/C Composites: Hybrid Mechanochemical Synthesis and Excellent Li Storage Performances. $J$. Mater. Chem. A 2013, I (48), 15316-15322. https://doi.org/10.1039/c3ta13972g.

(31) Whittingham, M. S. History, Evolution, and Future Status of Energy Storage. Proc. IEEE 2012, 100 (SPL CONTENT), 1518-1534. https://doi.org/10.1109/JPROC.2012.2190170.

(32) Weker, J. N.; Liu, N.; Misra, S.; Andrews, J. C.; Cui, Y.; Toney, M. F. In Situ Nanotomography and Operando Transmission X-Ray Microscopy of Micron-Sized Ge Particles. Energy Environ. Sci. 2014, 7 (8), 2771-2777. https://doi.org/10.1039/c4ee01384k.

(33) Fecht, H. J. Nanostructure Formation by Mechanical Attrition. Nanostructured Mater. 1995, 6 (1-4), 33-42. https://doi.org/10.1016/0965-9773(95)00027-5.

(34) Meyers, M. A.; Mishra, A.; Benson, D. J. Mechanical Properties of Nanocrystalline Materials. Prog. Mater. Sci. 2006, 51 (4), 427-556. https://doi.org/10.1016/j.pmatsci.2005.08.003.

(35) Zhang, X.; Wang, H.; Narayan, J.; Koch, C. C. Evidence for the Formation Mechanism of Nanoscale Microstructures in Cryomilled Zn Powder. Acta Mater. 2001, 49 (8), 1319-1326. https://doi.org/10.1016/S1359-6454(01)00051-9.

(36) Mohamed, F. A. A Dislocation Model for the Minimum Grain Size Obtainable by 
Milling. Acta Mater. 2003, 51 (14), 4107-4119. https://doi.org/10.1016/S13596454(03)00230-1.

(37) Vigolo, B.; Penicaud, A.; Coulon, C.; Sauder, C.; Pailler, R.; Journet, C.; Bernier, P.; Poulin, P. Macroscopic Fibers and Ribbons of Oriented Carbon Nanotubes. Science (80-. ). 2000, 290 (5495), 1331-1334.

https://doi.org/10.1126/science.290.5495.1331.

(38) Shaffer, B. M. S. P.; Windle, A. H. Fabrication and Characterization of Carbon Nanotube / Poly ( Vinyl Alcohol ) Composites **. 1999, 937-941.

(39) Lee, J. H.; Marroquin, J.; Rhee, K. Y.; Park, S. J.; Hui, D. Cryomilling Application of Graphene to Improve Material Properties of Graphene/Chitosan Nanocomposites. Compos. Part B Eng. 2013, 45 (1), 682-687. https://doi.org/10.1016/j.compositesb.2012.05.011.

(40) Omidi, M.; Khodabandeh, A.; Nategh, S.; Khakbiz, M. Wear Mechanisms Maps of CNT Reinforced Al6061 Nanocomposites Treated by Cryomilling and Mechanical Milling. Tribol. Int. 2017, 110 (October 2016), 151-160. https://doi.org/10.1016/j.triboint.2017.01.033.

(41) Woo, D. J.; Hooper, J. P.; Osswald, S.; Bottolfson, B. A.; Brewer, L. N. Low Temperature Synthesis of Carbon Nanotube-Reinforced Aluminum Metal Composite Powders Using Cryogenic Milling. J. Mater. Res. 2014, 29 (22), 26442656. https://doi.org/10.1557/jmr.2014.300.

(42) Xing, T.; Ramireddy, T.; Li, L. H.; Gunzelmann, D.; Zeng, H.; Qi, W.; Zhou, S.; Chen, Y. Lithium Storage in Disordered Graphitic Materials: A Semi-Quantitative Study of the Relationship between Structure Disordering and Capacity. Phys. Chem. Chem. Phys. 2015, 17 (7), 5084-5089. https://doi.org/10.1039/c4cp05589f.

(43) Ferrari, A. C.; Robertson, J. Resonant Raman Spectroscopy of Disordered, Amorphous, and Diamondlike Carbon. Phys. Rev. B 2001, 64 (7), 75414. https://doi.org/10.1103/PhysRevB.64.075414.

(44) Ferrari, A. C.; Robertson, J. Interpretation of Raman Spectra of Disordered and Amorphous Carbon. Phys. Rev. B 2000, 61 (20), 14095-14107. https://doi.org/10.1103/PhysRevB.61.14095.

(45) Azeez, A. A.; Rhee, K. Y.; Park, S. J.; Kim, H. J.; Jung, D. H. Application of Cryomilling to Enhance Material Properties of Carbon Nanotube Reinforced Chitosan Nanocomposites. Compos. Part B Eng. 2013, 50, 127-134. https://doi.org/10.1016/j.compositesb.2013.01.010. 


\title{
Supporting Information
}

\section{A Cryogenic Milling Method to Fabricate Nanostructured Anodes}

\author{
Qizhang Yan', Shu-Ting Ko², Yumin Zhao', Grace Whang³, Andrew \\ Dawson ${ }^{4}$, Sarah H. Tolbert ${ }^{3,4}$, Bruce S. Dunn³, and Jian Luo ${ }^{1,2, *}$ \\ 1Department of Nanoengineering; ${ }^{2}$ Program of Materials Science and \\ Engineering, University of California San Diego, La Jolla, California 92093, \\ U.S.A. \\ ${ }^{3}$ Department of Materials Science and Engineering; ${ }^{4}$ Department of Chemistry \\ and Biochemistry, University of California, Los Angeles, California 90095, \\ U.S.A.
}

*Corresponding author: jluo@alum.mit.edu 


\section{Supplementary Table}

Table S1. Averaged grain size and strain estimation using Williamson-Hall (W-H) analysis from XRD patterns shown in Figure 1d.

\begin{tabular}{ccc}
\hline & Grain Size $(\mathbf{n m})$ & Strain \\
\hline High-Energy Ball Mill & 41.7 & 0.0028 \\
Planetary Ball Mill & 59.2 & 0.0030 \\
Cryogenic Ball Mill & 23.5 & 0.0020 \\
\hline
\end{tabular}




\section{Supplementary Figures}

(a)

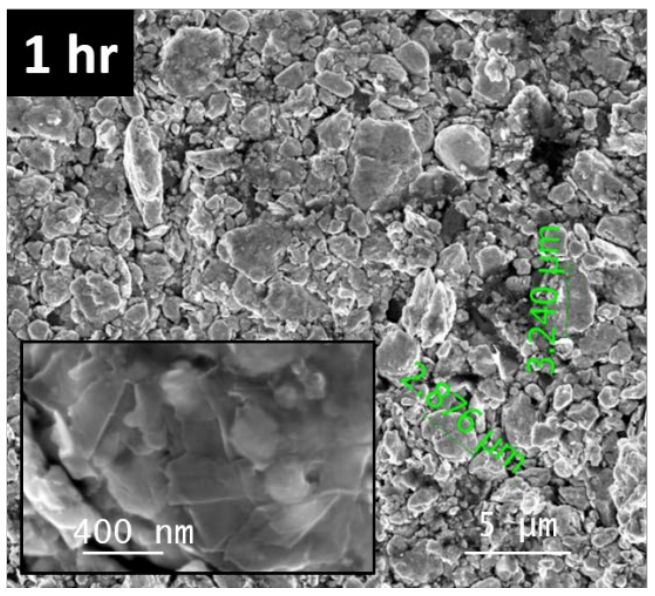

(b)

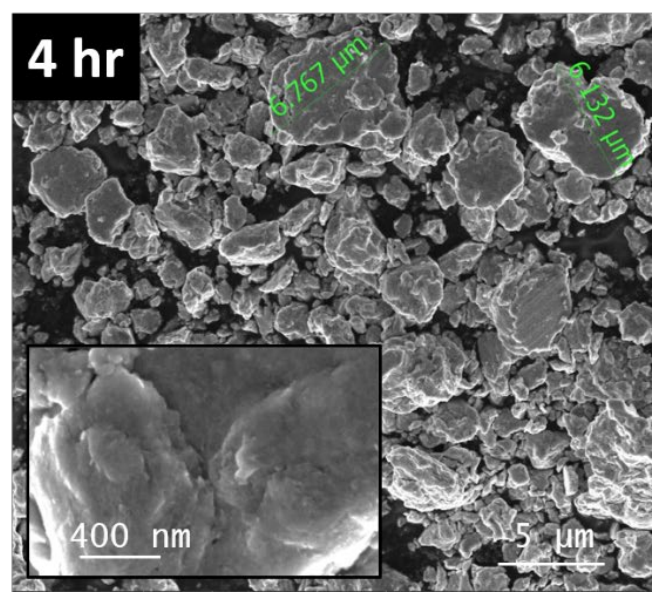

Figure S1. SEM characterization of the cryomilled SnSb-C composite powder morphologies after milling for (a) 1 hour and (b) 4 hours, respectively. 

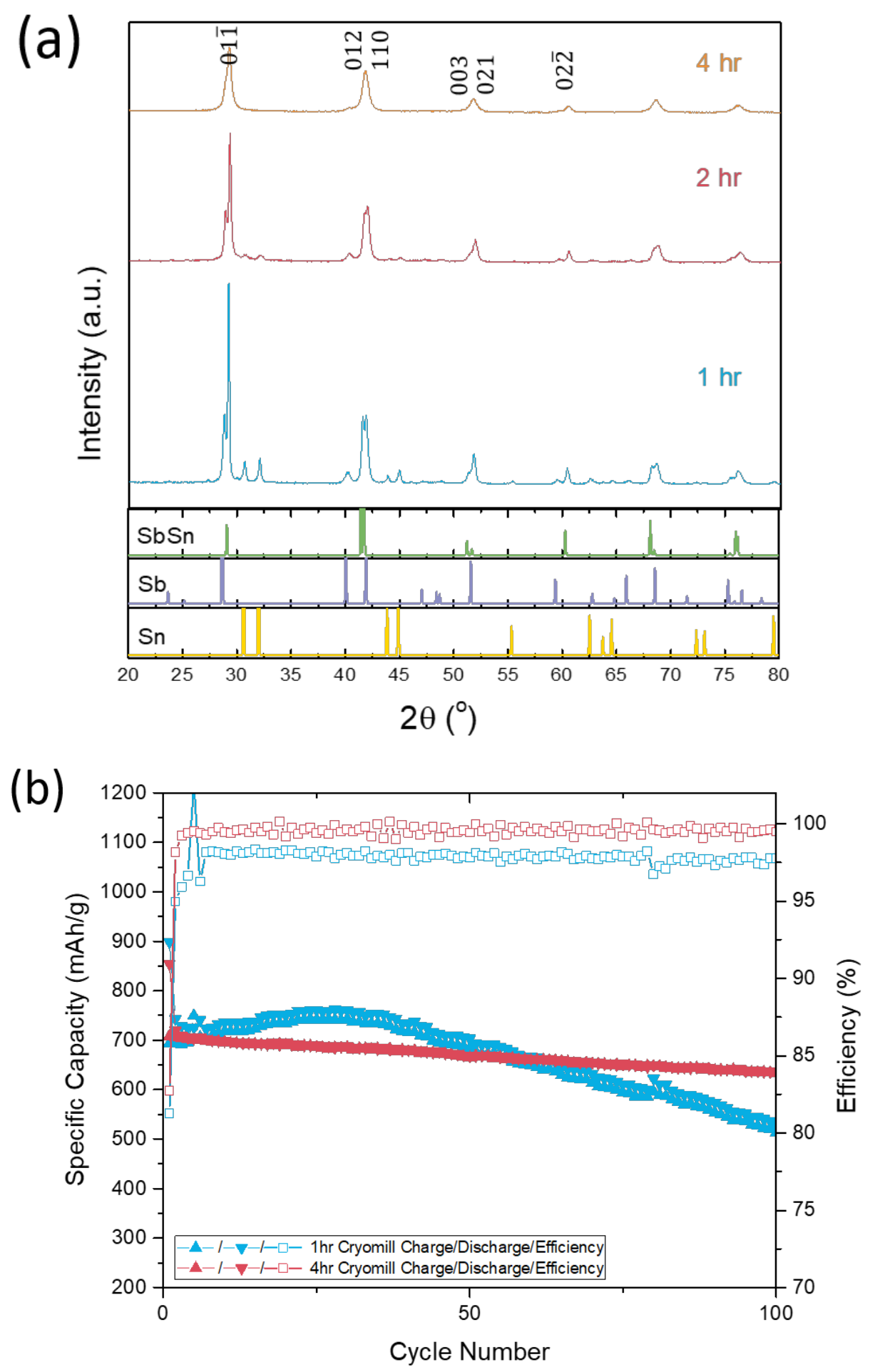

Figure S2. (a) XRD and (b) cycling performance comparison of the cryomilled SnSb-C composites with different milling durations. The cells were cycled at $100 \mathrm{~mA} / \mathrm{g}$ with the voltage range of $0.05 \mathrm{~V}-1.5 \mathrm{~V}$. 
(a)

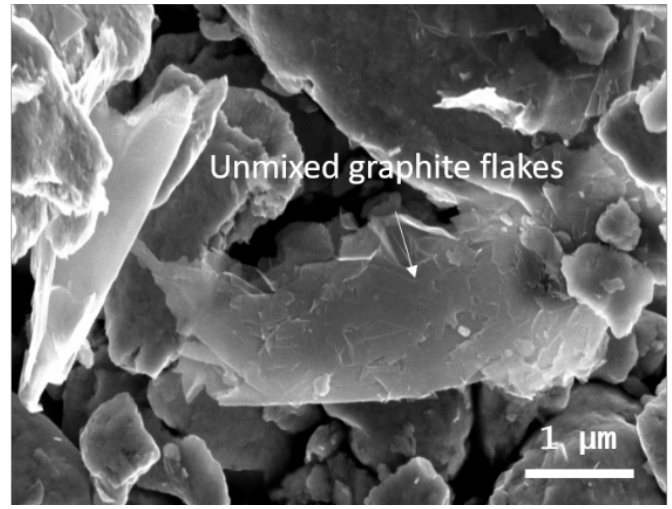

(b)

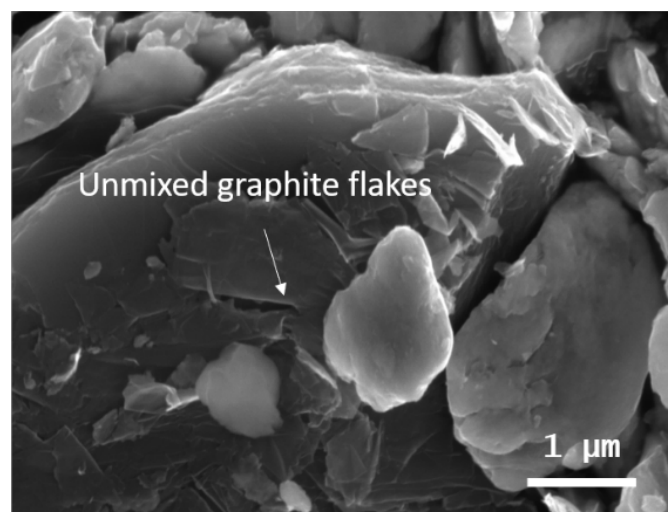

Figure S3. Unmixed graphite flakes found in the 8-hour planetary ball milled SnSb-C composite powder. 


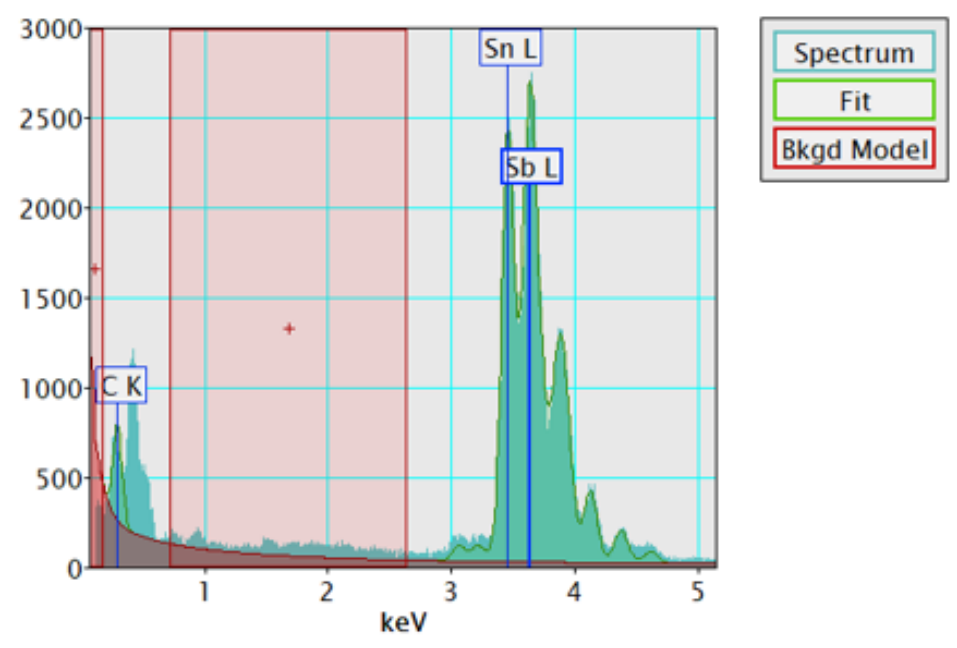

Figure S4. EDS spectrum fitting for the cryomilled SnSb-C sample. 

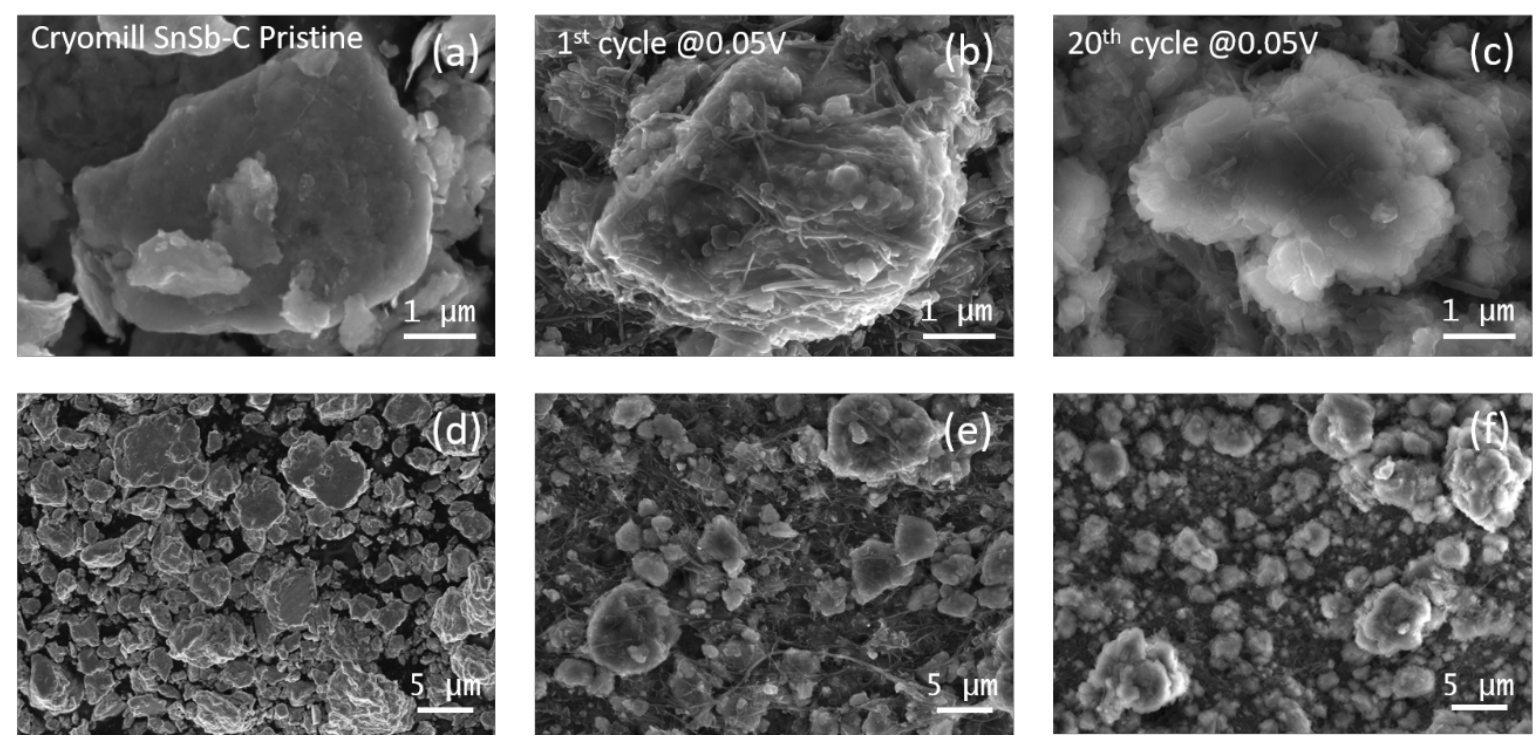

Figure S5. The morphology changes in the cryomilled SnSb-C composite upon cycling at high-magnification and low-magnification views. (a) (d) Pristine, (b) (e) after initial lithiation, and (c) (f) after 20 cycles. 

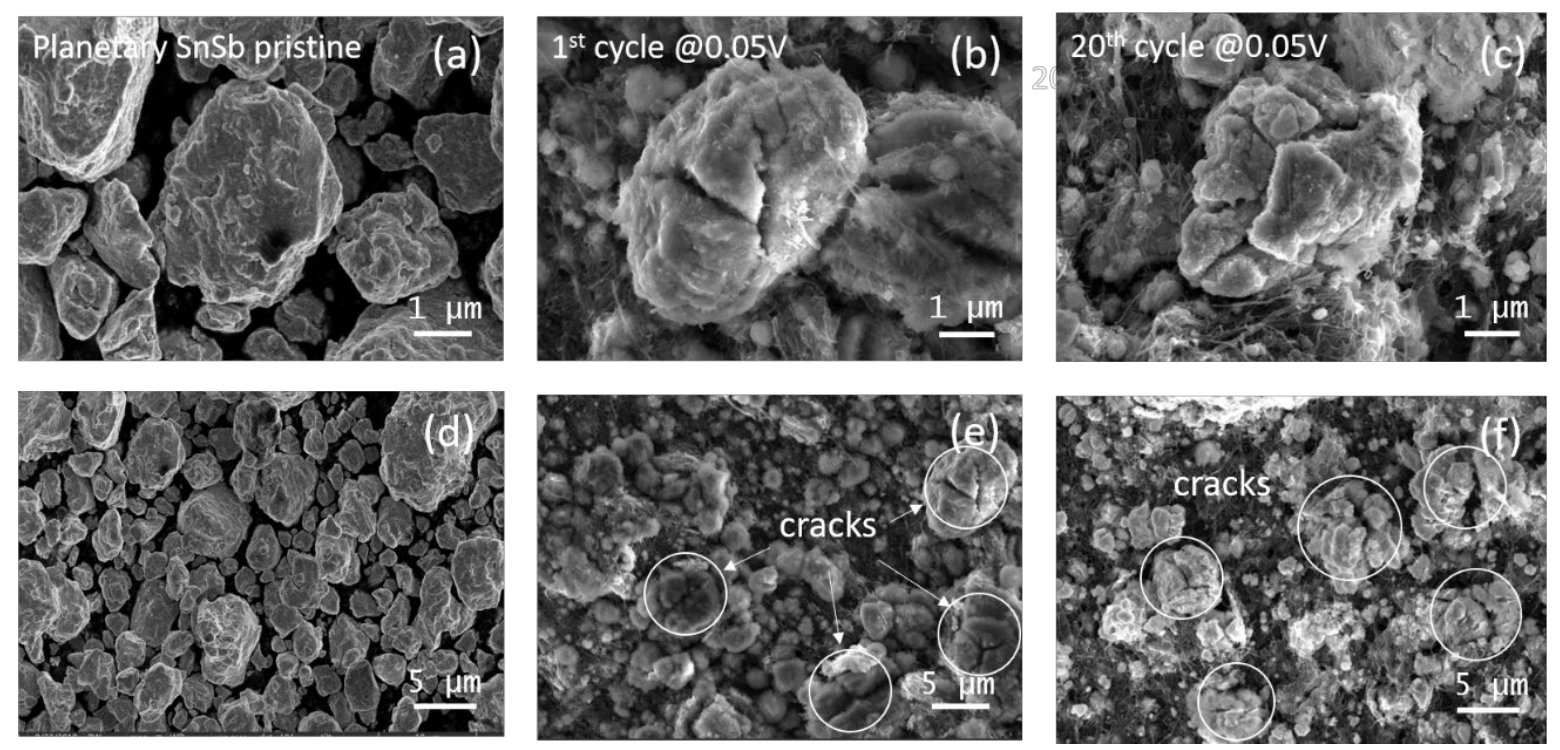

Figure S6. The morphology changes of the planetary ball milled SnSb-C composite upon cycling at high-magnification and low-magnification views. (a) (d) Pristine, (b) (e) after initial lithiation, and (c) (f) after 20 cycles. 

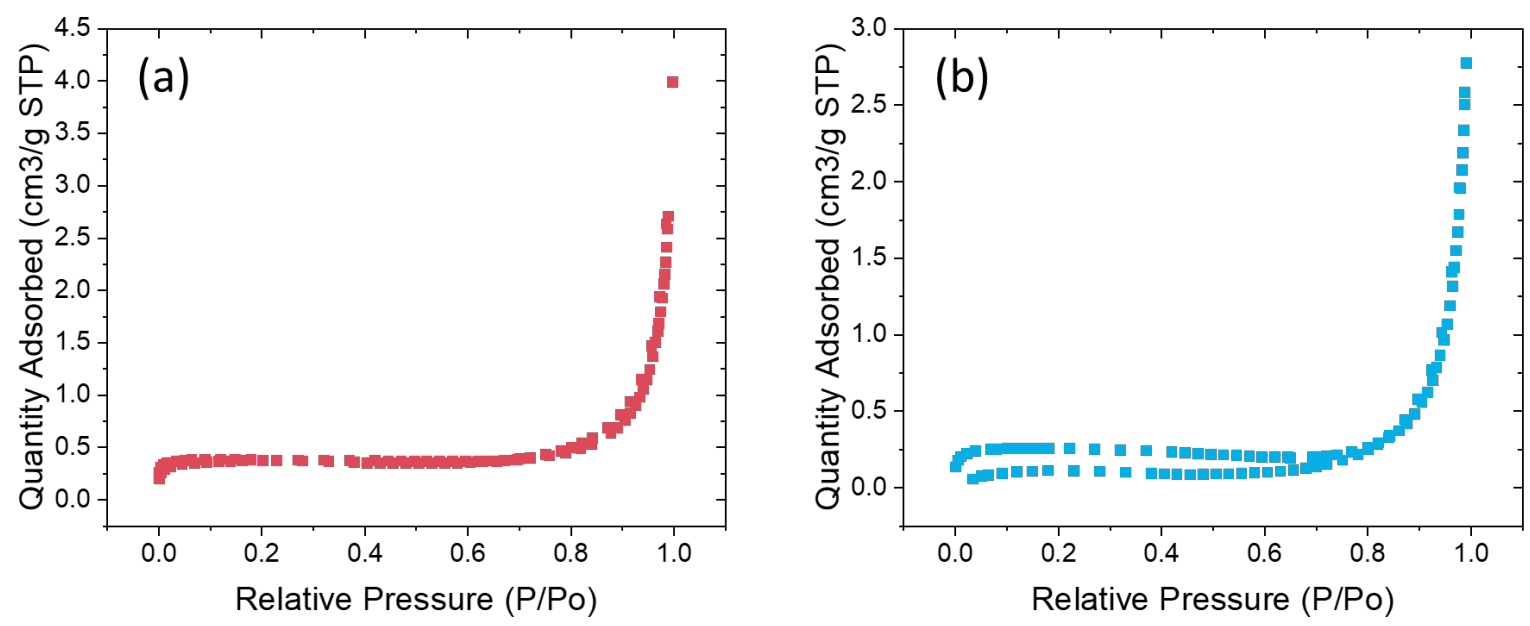

Figure S7. Absorption isotherm of (a) planetary ball milled sample and (b) cryomilled sample obtained from nitrogen porosimetry. 


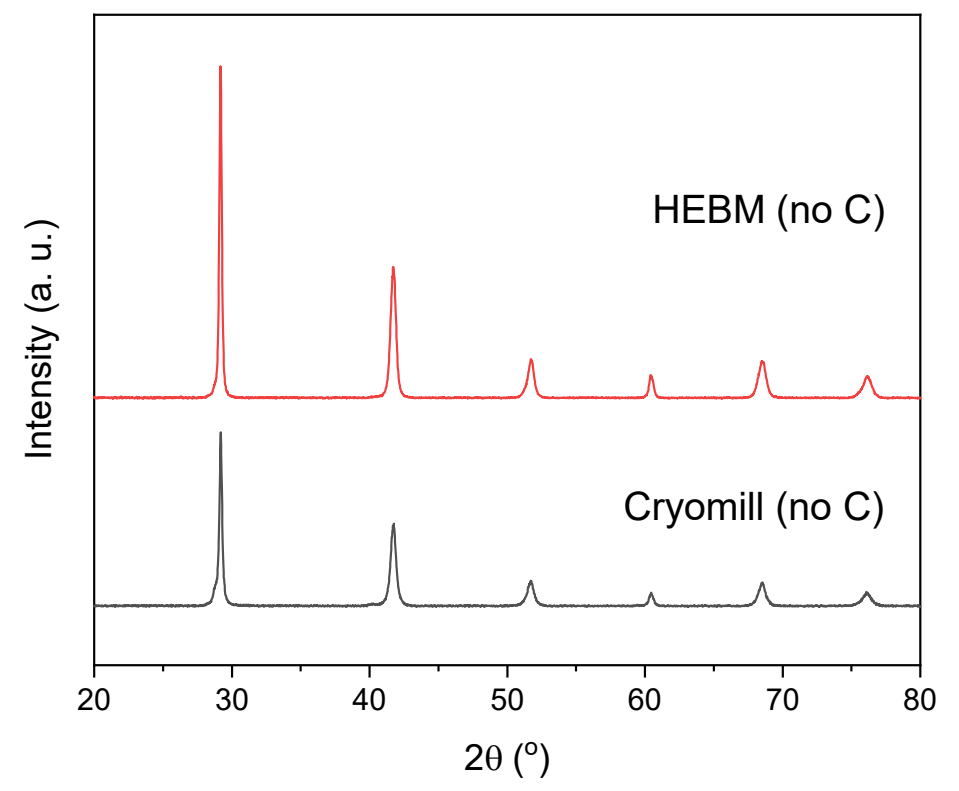

Figure S8. XRD comparison of the $\mathrm{SnSb}$ samples (without carbon addition) fabricated with high-energy ball mill and cryomill. 


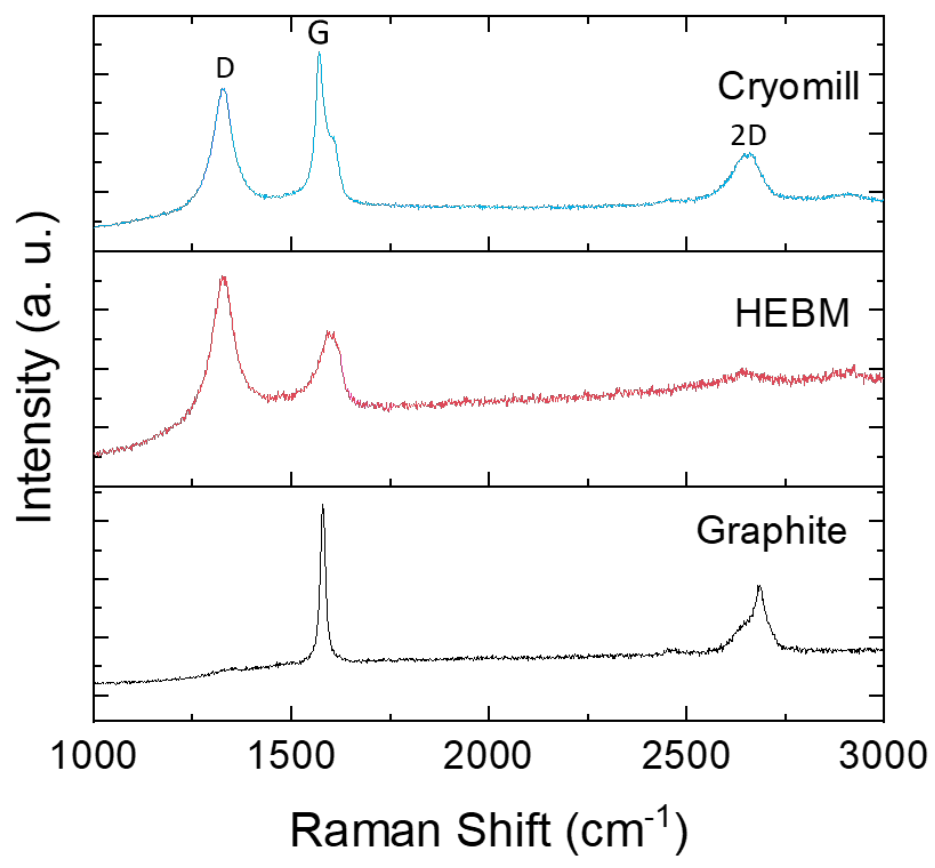

Figure S9. Raman spectroscopy comparison of the $\mathrm{SnSb}-\mathrm{C}$ sample after cryomill and highenergy ball mill. The baseline is graphite sample without ball milling. 


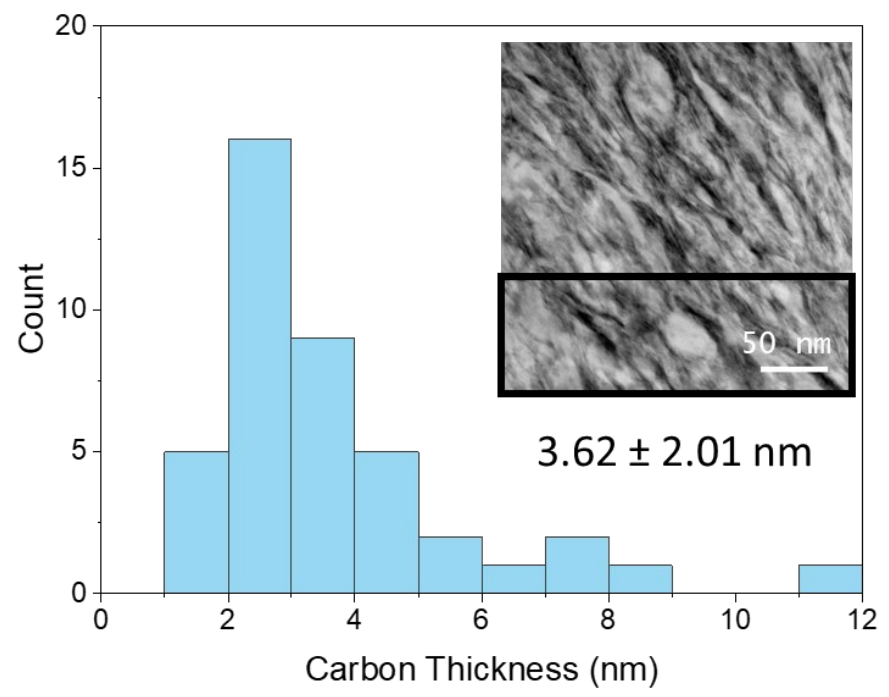

Figure S10. Measured carbon thickness histogram of the 4 hour cryomilled SnSb-C composite sample. 40 locations of carbon thickness were measured within the boxed region of the STEM HAADF image (Figure 2c). Carbon corresponds to the dark contrast region in the HAADF image. 

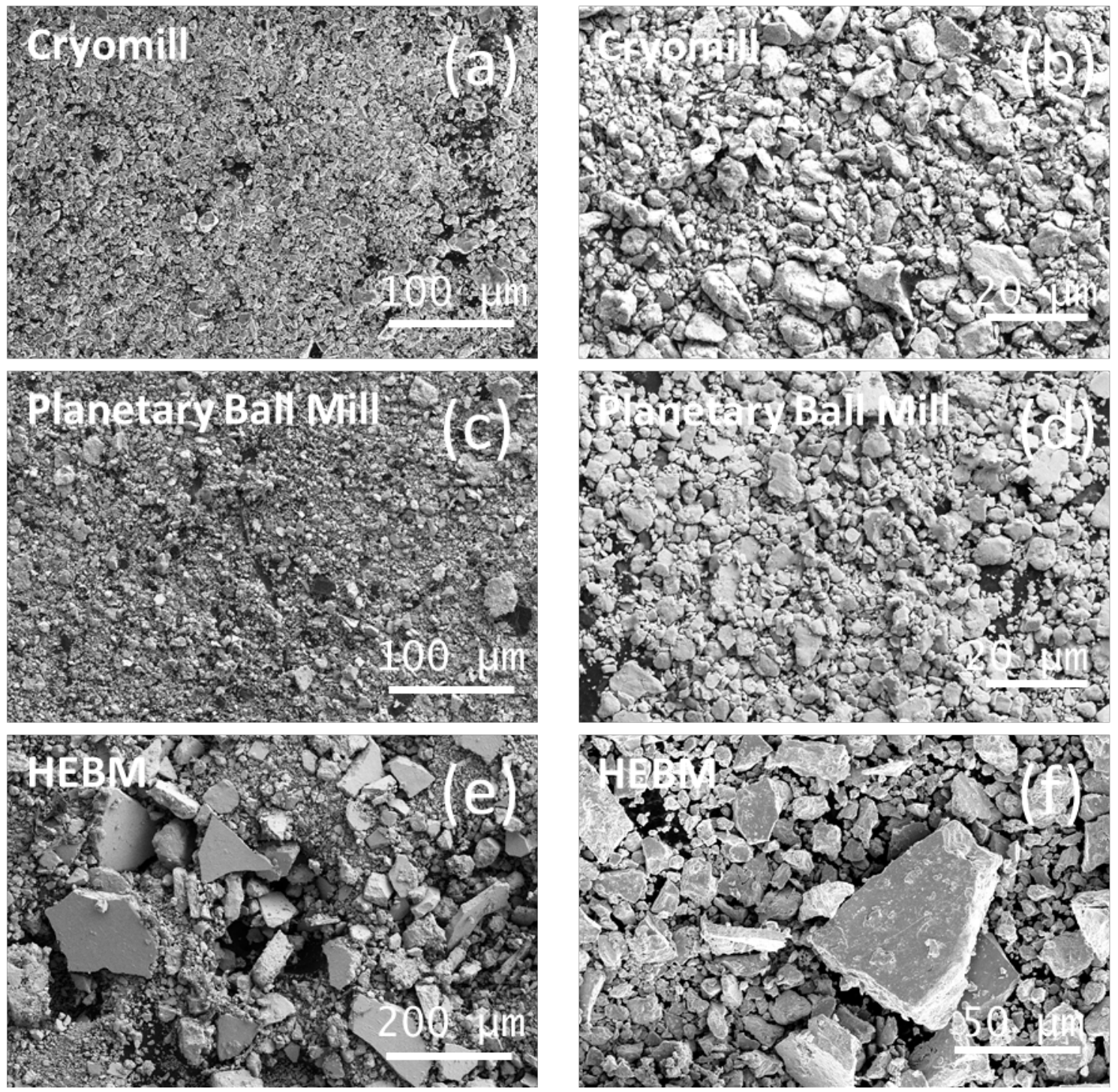

Figure S11. Low magnification SEM images of mechanical alloyed SnSb-C composite anodes fabricated through (a) (b) cryogenic ball mill, (b) (c) planetary ball mill, and (e) (f) high-energy ball mill. 

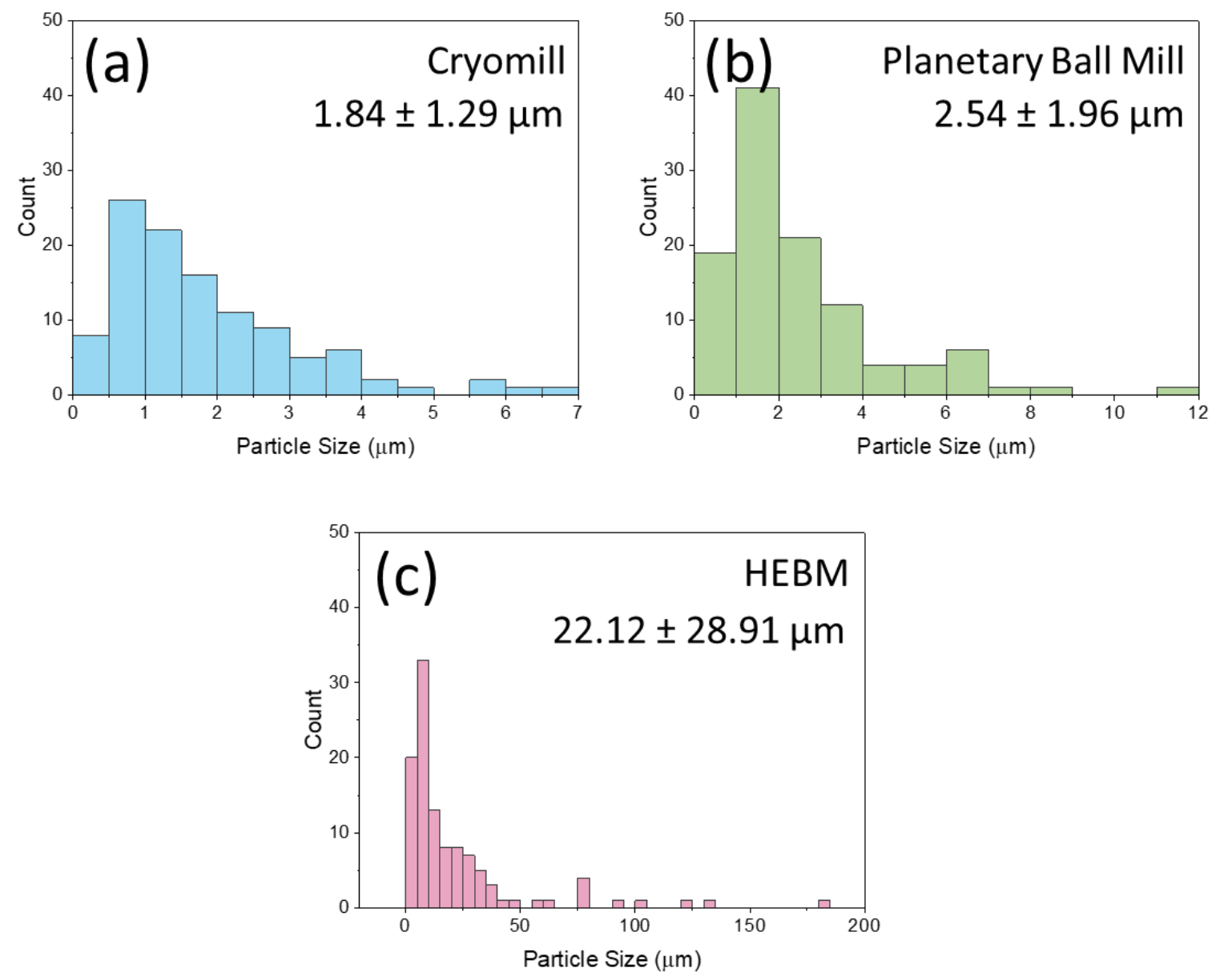

Figure S12. Particle size distribution of (a) cryogenic ball mill, (b) planetary ball mill, and (c) high-energy ball mill. 